January 2019

\title{
Comparison Of Concurrent Radar And Aircraft Measurements Of Cirrus Clouds
}

Nicholas James Gapp

\section{How does access to this work benefit you? Let us know!}

Follow this and additional works at: https://commons.und.edu/theses

\section{Recommended Citation}

Gapp, Nicholas James, "Comparison Of Concurrent Radar And Aircraft Measurements Of Cirrus Clouds" (2019). Theses and Dissertations. 2555.

https://commons.und.edu/theses/2555

This Thesis is brought to you for free and open access by the Theses, Dissertations, and Senior Projects at UND Scholarly Commons. It has been accepted for inclusion in Theses and Dissertations by an authorized administrator of UND Scholarly Commons. For more information, please contact und.commons@library.und.edu. 


\title{
COMPARISON OF CONCURRENT RADAR AND AIRCRAFT MEASUREMENTS OF CIRRUS CLOUDS
}

by

\author{
Nicholas James Gapp \\ Bachelor of Science, University of North Dakota, 2016 \\ Master of Science, University of North Dakota, 2019
}

\author{
A Thesis \\ Submitted to the Graduate Faculty \\ of the \\ University of North Dakota \\ in partial fulfillment of the requirements
}

for the degree of
Master of Science

Grand Forks, North Dakota

August

2019 
Copyright 2019 Nicholas James Gapp 
This thesis, submitted by Nicholas James Gapp in partial fulfillment of the requirements for the Degree of Master of Science from the University of North Dakota, has been read by the Faculty Advisory Committee under whom the work has been done and is hereby approved.

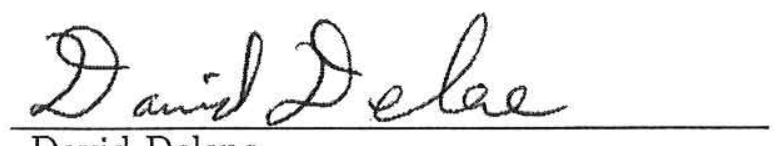

David Delene

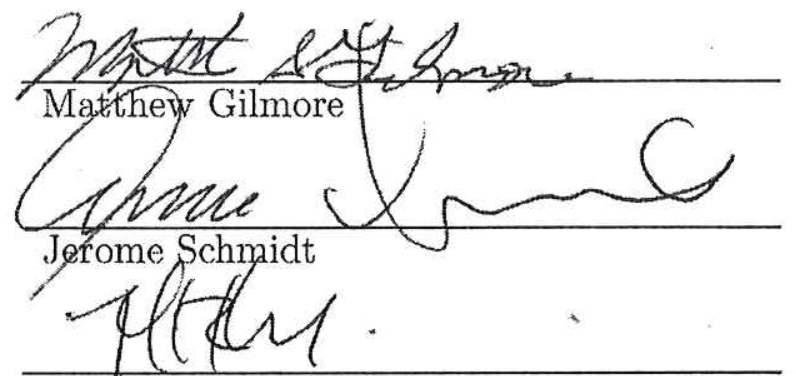

Pail Harasti

This thesis is being submitted by the appointed advisory committee as having met all of the requirements of the School of Graduate Studies at the University of North Dakota and is hereby approved.

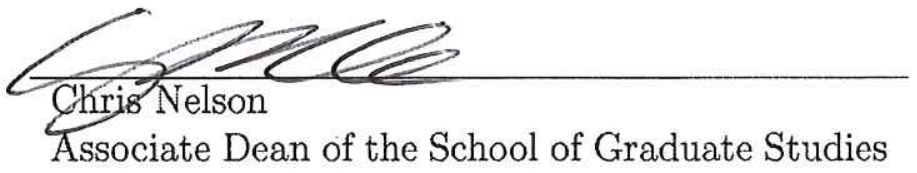

$7 / 30 / 19$ 


\section{PERMISSION}

Title Comparison of Concurrent Radar and Aircraft Measurements of Cirrus Clouds

Department Atmospheric Sciences

Degree $\quad$ Master of Science

In presenting this thesis in partial fulfillment of the requirements for a graduate degree from the University of North Dakota, I agree that the library of this University shall make it freely available for inspection. I further agree that permission for extensive copying for scholarly purposes may be granted by the professor who supervised my thesis work or, in his absence, by the Chairperson of the department or the dean of the School of Graduate Studies. It is understood that any copying or publication or other use of this thesis or part thereof for financial gain shall not be allowed without my written permission. It is also understood that due recognition shall be given to me and to the University of North Dakota in any scholarly use which may be made of any material in my thesis.

Nicholas James Gapp

19 July 2019 


\section{TABLE OF CONTENTS}

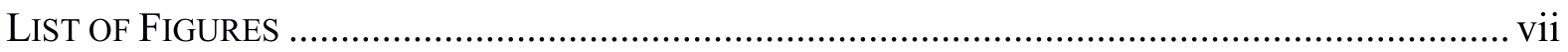

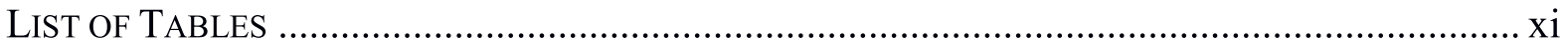

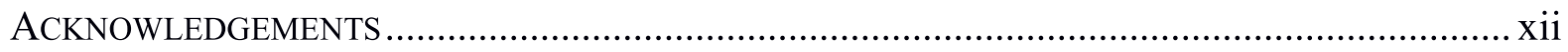

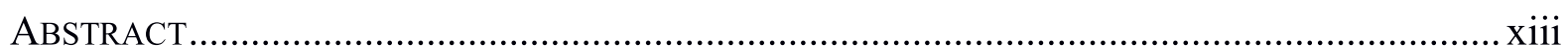

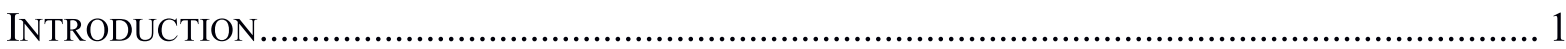

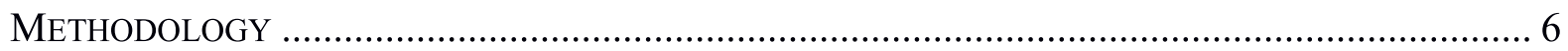

Aircraft Measurements ............................................................................................... 6

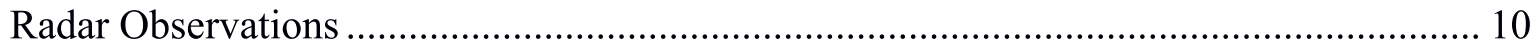

Aircraft and Radar Data Comparisons ....................................................................... 14

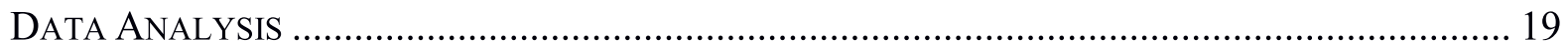

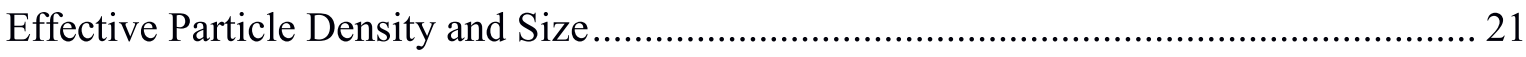

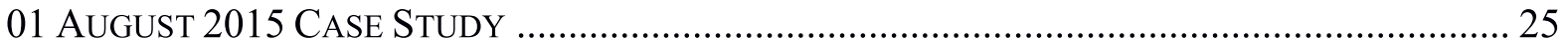

MCR Reflectivity-Total Water Content Relationship................................................. 29

Comparisons of Radar Reflectivity Factor............................................................. 31

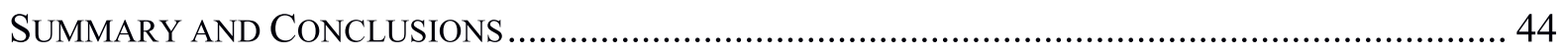

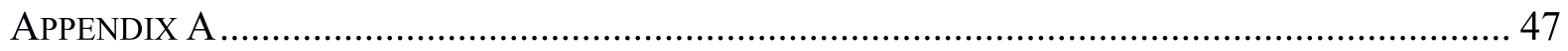


APPENDIX B

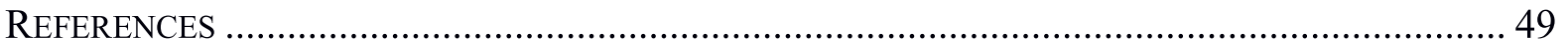




\section{LIST OF FIGURES}

1 The suite of externally mounted instruments on the Citation Research Aircraft is shown. Cloud physics instruments are the High Volume Particle Spectrometer Version 3 (HVPS3) probe, the Two-Dimensional Cloud (2D-C) probe, the Cloud Droplet Probe (CDP), and the Two-Dimensional Stereographic (2D-S) probe. Aerosol instruments are the Condensation Particle Counter (CPC) in the cabin (air intake labeled) and the Passive Cavity Aerosol Spectrometer Probe (PCASP). Water content instruments are the King Hot Wire Probe ("Hot Wire LWC Probe"), the Nevzorov Water Content Probe ("Nevzorov Probe"), and the Rosemount Ice Detector ("Icing Probe"). Atmospheric state parameters are measured with the Tunable Diode Laser Hygrometer (TDL) in the cabin (air intake labeled), Edgetech Chilled Mirror Dew Point Sensor Probe ("Dew Point Temp.") in the cabin (air intake labeled), the Five-Port Gust Probe ("Nose Boom Gust Probe"), the Tropospheric Airborne Meteorological Data Reporting (TAMDAR) probe, and two temperature probes ("Temp. Probe"). The aircraft includes an ultra-high frequency (UHF) antenna for long range communication, several GPS antennas, and satellite communication antennas. Miscellaneous instruments include an Optical Window for optical ice detectors in the cabin and various Pitot Tubes for measuring the aircraft's air speed.

2 The radar reflectivity factor from the narrowband beam of the MCR (shading) and the height of the aircraft (red line) are shown during a segment of a research flight on 01 August 2015. The "stripe" of high radar reflectivity factor between $11-11.5 \mathrm{~km}$ (approximately $3.5 \mathrm{~km}$ in along-beam range) is contamination from the high reflectivity returns caused by the Citation Research Aircraft. Altitude (AGL) of the beam at each range gate (y-axis) is derived per pulse using the distance at each range gate and the elevation angle. The altitude calculations are based on the 4/3 Earth's radius model [Equation 2.28b from Doviak and Zrnić (1984)]. Note the range to the aircraft is constantly changing since the MCR is tracking the aircraft during this period, but the range and altitude are plotted using only the first shown pulse's range and altitude.

3 Merged particle size spectra from the 2D-S and HVPS3 probes are shown for four aircraft flights. The legend times are in Universal Coordinated Time (UTC) seconds from midnight on the day the flight started (sfm). The legends give the 60 second time periods analyzed from within the segments given in Table 3 . The particle concentrations are normalized by the log of the size bin created during 
data post-processing, and the diamonds are the midpoints of the size bins. Discontinuities in the lines are the result of $0 \# \mathrm{~cm}-3$ concentrations for a size bin.

The effective particle densities $\left(\rho_{e}\right.$, Equation 2$)$ per median volume diameter $\left(D_{v}\right)$ are shown for the four CAPE2015 field project flights (colored dots) outlined in Table 2. Each data point is an average over $1 \mathrm{~s}$. The line of best fit via a power law regression (solid black line) and the upper and lower bounds of the $95 \%$ confidence interval (dashed black lines) are discussed in the text. The red lines show relationships reported in previous studies. The dashed red line (H2004) represents the D- $\rho_{e}$ relationship of convective cases during CRYSTALFACE from Heymsfield et al. (2004). The dotted line (C2013) and dash-dotted line (BF1995) use mass-dimensional relationships from Cotton et al. (2013) and Brown and Francis (1995), respectively, to derive the $\rho_{e}$ values from the reported mass-dimensional relationships for the times of analysis described in Table 2 . ...

The frequency distribution of $1 \mathrm{~Hz}$ effective liquid particle sizes (Equation 1) is shown for the times described in Table 2 . Note that $89.2 \%$ of the liquidequivalent diameters are above $50 \mu \mathrm{m}$ in diameter.

6 The four in-cloud flight segments during which the aircraft was tracked in realtime by the MCR on 01 August 2015 are shown. The aircraft flight segment times in Universal Coordinated Time (UTC) seconds from midnight on the day of the flight (sfm) are: 71,154-71,277 sfm (AC13, red line); 71,717-71,903 sfm (AC14, green line); 72,425-72,500 sfm (AC15, blue line); and 72,530-72,839 sfm (AC16, orange line).

7 Visible satellite images from GOES15 on 01 August 2015 in Universal Coordinated Time (UTC) at 18:00 UTC (a) and 21:00 UTC (b) are shown. The locations of the MCR radar, the Space Coast Regional Airport (KTIX, homebase for flight operations), and select cities are labeled.

Base reflectivity on 01 August 2015 from the National Weather Service Melbourne radar (KMLB) and flight tracks (white line) during each MCR data file case is shown. The base reflectivity images shown are the closest available scans to the mean time of each flight segment. Arrows are included to depict the aircraft's direction of travel.

9 Cross-sections of the radar returns on 01 August 2015 from the National Weather Service Melbourne radar (KMLB) is shown for each case shown in Figure 8. Each cross-section is taken along the direction of travel of the aircraft except in (d) where it is taken along a line beginning at the apex of the aircraft's turn and ending at the approximate midpoint between the starting and ending points of the flight leg.

10 Plot showing the 1 second-averaged MCR reflectivity and corresponding 1 
second-averaged Nevzorov total water content (TWC, blue dots) for the aircraft tracking cases AC13-AC16 on 01 August 2015. The solid black line represents the power law line of best fit to the data with the equation in the legend where TWC is the total water content $\left(\mathrm{g} \mathrm{m}^{-3}\right)$ and $\mathrm{Z}$ is the reflectivity factor $\left(\mathrm{mm}^{6} \mathrm{~m}^{-3}\right)$. The upper and lower bounds of the $95 \%$ confidence interval in the fit are shown in the dashed black lines. The red lines represent the radar reflectivity-ice water content relationships reported in previous studies: Heymsfield (1977) (H1997, solid line), Sassen (1987) (S1987, dash-dot line), Heymsfield et al. (2005) (H2005, dotted line), and Sayres et al. (2008) (S2008, dashed line).

11 Comparisons between the MCR-observed reflectivity (blue lines) and aircraftderived reflectivity (black lines) at $1 \mathrm{~Hz}$ for all four aircraft tracking scanning strategy cases are shown. The MCR-observed wideband reflectivity shown is an average of $10 \mathrm{~m}$ in range surrounding the aircraft $( \pm 5 \mathrm{~m}$ in range from range of aircraft). The upper and lower uncertainty (unc.) bounds are plotted with dotted lines for both the MCR-observed reflectivity (dotted blue lines) and derived reflectivity (dotted black lines). $\mathrm{A} \pm 3 \mathrm{dBZ}$ uncertainty in the MCR-observed reflectivity is assumed. The uncertainty bounds for the derived reflectivity are derived from $\delta z$ in Equation 6.

12 MCR-observed and aircraft-derived reflectivity is shown as in Figure 11 but for an average of 10 seconds.

13 The particle size distributions (PSDs) for aircraft tracking cases AC13-AC16 are shown. The 2D-S particle concentrations are shown below $1,000 \mu \mathrm{m}$ and the HVPS3 particle concentrations are shown from 1,000 $\mu \mathrm{m}$ and above ("merged PSD"). Each PSD represents the average particle concentrations during the entirety of each tracking case in seconds from midnight (sfm): AC13 is from 71154.2-71277.7 sfm, AC14 is from 71717.4-71903.3 sfm, AC15 is from $72425.5-72500.0 \mathrm{sfm}$, and AC16 is from 72530.0-72839.1 sfm. The particle concentrations are normalized by the log of the size of each size bin created during SODA2 processing, and the diamonds represent the midpoints of those size bins.

14 Data collected from the Citation Research Aircraft during the AC14 tracking case on 01 August 2015 is shown. Plot (a) shows the GPS altitude of the aircraft (black line) and corresponding ambient air temperature (blue line) per time in seconds from midnight (sfm). The vertical lines labeled 1-3 correspond to particle images in plot (c) from the Two-Dimensional Stereographic (2D-S) probe. Plot (b) shows the mean log-normalized particle size distribution of the observed particles from the 2D-S (black line) and HVPS-3 (blue line) for particles greater than 105 um over the entirety of the AC14 case. The diamonds represent the midpoint of each $2 \mathrm{D}-\mathrm{S}$ size bin created during data post-processing. Plot (c) shows 2D-S particle images from various times during case AC14. Image (1) is at $71750 \mathrm{sfm}$, image (2) is at $71826 \mathrm{sfm}$, and image (3) is at 71849 sfm. The horizontal axis of each rectangle containing particle images is time and 
the vertical axis is along the array of photodiodes (128 dots representing 1280 $\mu \mathrm{m}$ in total size). Measurements by the 2D-S are taken asynchronously so the horizontal axes of each rectangle containing the images represent different lengths of time, but each segment 1-3 represents approximately $0.5 \mathrm{~s}$ of particle data. Plot (d) shows the mean distribution of derived reflectivity from the probe data over the entirety of the AC14 case. The diamonds represent the midpoints of each size bin created during data post-processing. ............................

15 Data pertaining to the calculation of the derived reflectivity during the AC14 case is shown. Plot (a) shows box-and-whisker plots of 1 second-averaged MCR-observed (left) and aircraft-derived (right) reflectivity data for case AC14. The middle red line is the median of the data; the bottom and top of each box is $25^{\text {th }}$ and $75^{\text {th }}$ percentiles, respectively; the whiskers extend to the furthest data points not considered outliers; and the red pluses are outliers within the data sets. The MCR reflectivity is an average of $10 \mathrm{~m}$ in range surrounding the aircraft $( \pm 5$ $\mathrm{m}$ in range from range of aircraft). Plot (b) shows the total particle concentration and total number of particles greater than $105 \mu \mathrm{m}$ (black and blue lines, respectively). Plot (c) shows the derived effective ice particle density (Equation 2). Plot (d) shows the sixth moment of the summation of the liquid-equivalent diameter of particles greater than $105 \mu \mathrm{m}$ (Equation 1). The numbered vertical lines in (b-d) correspond to the times of the Two-Dimensional Stereographic (2D-S) probe particle images in Figure 14c.

16 Data collected from the Citation Research Aircraft is shown as in Figure 14 but for case AC13 on 01 August 2015. The vertical lines (1-3) in plot (a) correspond with the samples of Two-Dimensional Stereographic probe (2D-S) particle images in plot (c). The times are in Universal Coordinated Time (UTC) seconds from midnight on the day of the flight (sfm): image (1) at $71167 \mathrm{sfm}$, image (2) at 71200 , and image (3) at $71240 \mathrm{sfm}$.

17 Data pertaining to the calculation of the derived reflectivity is shown as in Figure 15 but for case AC13 case on 01 August 2015. The numbered vertical lines in (b-d) correspond to the times of the Two-Dimensional Stereographic probe (2DS) particle images in Figure 16c. 


\section{LIST OF TABLES}

Table

Page

1 Comparison of properties of the Mid-Course Radar (MCR), the University of North Dakota (UND) Weather Surveillance Radar 1974-C (WSR-74C), and the National Weather Service (NWS) Weather Surveillance Radar 1988-D (WSR88D) systems is shown. The values have been adapted from Schmidt et al. (2019) and Rinehart (2010), with additions from University of North Dakota (2004) and NOAA (2017). The MCR narrowband (NB) and wideband (WB) beam properties are listed separately when appropriate. The calculation of the 50 $\mathrm{km}$ sensitivity of the MCR is described in Appendix B.

2 Shown are the CAPE2015 field project in-cloud segments with level flight and temperatures below $-30{ }^{\circ} \mathrm{C}$. The start and end times of each segment are in Universal Coordinated Time (UTC) seconds from midnight on the day of the flight $(\mathrm{sfm})$. The minimum and maximum altitudes $(\mathrm{m})$ and temperatures $\left({ }^{\circ} \mathrm{C}\right)$ during each segment are given. The last column provides the amount of each segment where the temperature is at or below $-30{ }^{\circ} \mathrm{C}$, the Nevzorov TWC is greater than $0.005 \mathrm{~g} \mathrm{~m}^{-3}$ (in-cloud), and the aircraft is level (pitch between $2.5^{\circ}$ and $\left.4.5^{\circ}\right)$

3 Analyzed time segments from four flights in Table 2 are shown. The start and end times of each segment are in Universal Coordinated Time (UTC) seconds from midnight on the day of the flight (sfm). The mean and standard deviation of the temperature, total particle concentration greater than $105 \mu \mathrm{m}$ in diameter, and median volume diameter (MVD) greater than $105 \mu \mathrm{m}$ in diameter for each time segment are given. 


\section{ACKNOWLEDGEMENTS}

This research is supported under a Naval Surface Warfare Center grant to conduct the CAPE2015 field project and analyze the subsequent data. The Author would like to thank Peter Jones, L3 Electronics Corporation, Anaheim, CA, for his work with the aircraft tracking algorithms. The Author would also like to gratefully acknowledge the hard work of the flight crew and everyone else involved with the collection and post-processing of the CAPE2015 field project data. 
I dedicate my thesis to my Mom and Dad. Without their love and support, none of this would have been possible. 


\begin{abstract}
Observations from a summer 2015 field project near the Cape Canaveral Air Force Station in Florida (CAPE2015 field project) are analyzed. The highly instrumented North Dakota Citation Research Aircraft and the U.S. Navy's Mid-Course Radar (MCR), a unique, high-resolution radar on the Atlantic coast of Florida, obtained concurrent measurements of thunderstorm anvil cirrus clouds during seven research flights. The MCR alternatively transmits two waveforms, a lower-resolution (narrowband) beam and a high-resolution (wideband) beam with along-beam range resolutions of $37 \mathrm{~m}$ and $0.5 \mathrm{~m}$, respectively. A specialized MCR scanning strategy allows the MCR to track the aircraft using the downlinked position information from the aircraft to set the wideband beam ahead of the aircraft in real-time, thus obtaining concurrent, high-resolution in-situ and remote observations. Equivalent radar reflectivity factor is derived and the associated uncertainties are calculated at 1 and 10 second averaging intervals. Both are compared with the wideband reflectivity factor and its associated uncertainties at the same averaging intervals for one flight during the CAPE2015 field project. The relationship between the wideband reflectivity factor $(Z)$ and measured total water content (TWC) is found to be $T W C=(0.0995 \pm$ $0.005) Z^{(0.492 \pm 0.0408)}$ which agrees with past field project results. An average of $95 \%$ of examined 1 second-averaged values of derived reflectivity factor and observed wideband reflectivity factor agree within their respective uncertainties across the sampled range of -20 to $20 \mathrm{dBZ}$; however, the agreement decreases to $71 \%$ of the values for 10 second averaging. Additional observations that include a wider range of thunderstorm cloud microphysical conditions ( $\mathrm{dBZ}$ values) will enable a more robust relationship to be developed, which will
\end{abstract}


enable a vertical profile of water content, with corresponding uncertainty, to be obtained using the MCR's wideband reflectivity factor. 


\section{INTRODUCTION}

Routine measurements of vertically integrated cloud water content are difficult to obtain using only in-situ or remote sensing measurements. Obtaining vertically integrated in-situ measurements is difficult because of the large time gaps between measurements at different cloud locations; however, in-situ measurements provide direct measurements of cloud particle size and water content. Remote sensing observations such as radar require a parameterization to convert the reflectivity factor measurement to cloud water content; however, the retrieval has a high spatial and temporal resolution. Using both in-situ and remote platforms together provides high resolution observations with a quantified uncertainty. It is the objective of the current research to use concurrent, state-of-the-art aircraft (in-situ) measurements and radar (remote) observations in order to obtain vertically integrated cloud water content that has a known uncertainty and covers a large area.

Many studies have related radar reflectivity factor derived from aircraft in-situ microphysical measurements to observed radar reflectivity (e.g. Houze et al. 1981; Brandes et al. 1995; Bringi et al. 1998; Frisch et al. 2000; Hudak et al. 2002; Heymsfield et al. 2005; Lawson and Zuidema 2009). Additionally, in-situ cloud water content has been related to radar reflectivity factor observed with surface radars (e.g. Heymsfield 1977; Sassen 1987; Matrosov 1997; Heymsfield et al. 2002; Wang and Sassen 2002). Several previous research projects have discussed methods for comparing aircraft and radar observations (e.g. Heymsfield et al. 2004; Cotton et al. 2013). However, large variability often exists between the aircraft and radar data due to the large separation between the in-situ and remote measurements. The summer 2015 field project conducted near the Cape Canaveral Air Force Station in Florida (hereafter referred to as the CAPE2015 field project) sufficiently reduces this separation. A specialized scanning 
methodology allowed the U.S. Navy's Mid-Course Radar (MCR) to track the aircraft and obtain concurrent radar and in-situ measurements for prolonged periods, a first in meteorology. One goal of the CAPE2015 field project is to relate the water content to radar reflectivity factor measurements, which enables the determination of vertical profiles of water content from radar returns. The parameterization of water content from the MCR will be applied to shipborne radar systems to obtain vertical profiles of water content world-wide. Another goal is to improve the scientific understanding of cloud systems by making observations to improve our understanding of cloud processes, which includes using vertical profiles of cloud water content to develop more realistic global weather models.

The Cirrus Regional Study of Tropical Anvils and Cirrus Layers-Florida Area Cirrus Experiment (CRYSTAL-FACE) conducted in southern Florida during the summer of 2002 was motivated by similar research questions. Six separate aircraft were used during CRYSTALFACE, including the North Dakota Citation Research Aircraft (Delene et al. 2019a). Most flights during the month-long CRYSTAL-FACE project were focused on Florida summertime convection and the resulting anvils (Jensen et al. 2004). A study by Heymsfield et al. (2004) used over 7 hours of in-situ measurements of thunderstorm anvils during CRYSTAL-FACE to derive effective ice particle densities for use in modelling and remote sensing applications. The derived effective ice particle densities were calculated by fitting a gamma distribution to each measured particle size distribution and by using the maximum particle dimensions measured by an optical array probe. The effective ice densities were found to be in the range of $200-400 \mathrm{~kg}$ $\mathrm{m}^{-3}$ for clouds with ice water content in the range of $0.02-0.11 \mathrm{~g} \mathrm{~m}^{-3}$. The relationships between effective ice density and diameter are valid for convectively-generated anvils dominated by bullet rosette and complex ice particle types. The authors identified shortcomings of the 
instruments used in deriving the densities such as the breakup of large ice particles in the probe inlets and an under sampling of large particles by the cloud water content instrument.

Cotton et al. (2013) calculated the effective ice particle density from a suite of cloud physics instruments that included a Two-Dimensional Stereographic probe (2D-S) and a Nevzorov Water Content Probe, both of which are used during the CAPE2015 field project. The aircraft measurements were taken within mid-latitude cirrus during a 2010 field campaign. The midlatitude cirrus clouds had small ice particles, typically between $20-800 \mu \mathrm{m}$ in diameter, and low ice water contents $\left(0.001-0.05 \mathrm{~g} \mathrm{~m}^{-3}\right)$ which were due to low temperatures and high humidity with respect to ice. Particles touching the end diodes of the optical array probes (e.g. the 2D-S) were disregarded from analysis, and particle size distributions were fit to log-normal or gamma distributions if the particle habit was determined to be ice crystals or ice aggregates, respectively. The fitted distributions were then normalized by both the ice particle diameter and the standard deviation of the distribution. Drift in the baseline total water content (TWC) measurements using a Nevzorov Water Content Probe were also corrected in order to accurately measure the low water contents. The authors concluded that particles less than $70 \mu \mathrm{m}$ in diameter have a constant effective ice density of $700 \mathrm{~kg} \mathrm{~m}^{-3}$ and larger particles follow a relationship between their mass (M) and their diameter (D) given by the equation $M=0.0257 D^{2.0}$.

Sassen (1987) derived an ice-equivalent radar reflectivity factor $\left[Z_{i}=1.18 Z_{c}\right.$ where $Z_{c}\left(\mathrm{~mm}^{6}\right.$ $\mathrm{m}^{-3}$ ) using the liquid-equivalent radar reflectivity factor from Smith (1984)] for use in deriving the ice mass content from upper portions of deep convection where there is an absence of large ice particles and water droplets. The authors reported a relation between ice mass content, $M$, and ice-equivalent radar reflectivity factor of $M=0.037 Z_{i}^{0.696}$. The reported relation is most suitable for K-band and millimeter wavelength radars. Heymsfield (1977) used two different 
vertically pointing Doppler radars to derive a relationship using measured ice water content to predict radar reflectivity factor of stratiform ice clouds at various altitudes, temperatures, and synoptic conditions. Solving for $Z$, the relationship between ice water content (IWC) and $Z$ is $I W C=10^{0.5051 \log z-1.4521}$. Sayres et al. (2008) and Heymsfield et al. (2005) used CRYSTALFACE data to relate ice water content and radar reflectivity factor. Sayres et al. (2008) related the ice water content from a total water and water vapor instrument onboard one aircraft to the observed radar reflectivity from a $94 \mathrm{GHz}$ radar mounted on a separate aircraft. The data were co-located within $2 \mathrm{~km}$ of each other which complicated the analysis due to the spatial and temporal differences between the data sets. The authors categorized uncertainties by their sources to determine the most efficient way to validate the derived relationships and found uncertainties of $\pm 20-30 \%$ due to the spatial and temporal differences between the data sets. Heymsfield et al. (2005) compared radar reflectivity-ice water content relationships obtained from two airborne radars at separate frequencies $(9.6$ and $94 \mathrm{GHz})$ and in-situ ice water content measurements of convectively generated cirrus anvils during CRYSTAL-FACE. The radar reflectivity-ice water content relationship was derived from a gamma distribution from observed particle size distributions and a power-law-type mass-dimension relationship. A single powerlaw relationship was found to not represent the larger particle sizes that contribute the most to radar reflectivity.

The CAPE2015 field project aims to improve upon past field projects; however, the measurement techniques and methodology are similar. Unlike previous studies, concurrent measurements between in-situ and remote platforms create a data set that is co-located both spatially and temporally. Due to the ability to track the Citation Research Aircraft by the MCR in real-time, the two platforms are able to sample the same part of a cloud at the same time 
regardless of aircraft altitude, speed, or direction of flight. Therefore, uncertainties due to spatial or temporal differences between the data are minimized. 


\section{METHODOLOGY}

The CAPE2015 field project employs a myriad of surface, aircraft, and remote sensing measurements (Schmidt et al. 2019); however, this study focuses on in-situ, cloud physics aircraft measurements and concurrent remote observations from a unique, high-resolution radar. The objectives are to compare derived equivalent radar reflectivity factor from the in-situ measurements with observed radar reflectivity factor and determine a relationship between equivalent radar reflectivity factor and ice water content. The comparisons presented are for Florida summertime thunderstorm anvil cirrus clouds observed during the CAPE2015 field project.

\section{Aircraft Measurements}

The North Dakota Citation Research Aircraft (Figure 1) conducted in-situ measurements of cirrus clouds in the anvils of thunderstorms during the CAPE2015 field project. The Citation Research Aircraft is equipped with instruments for measuring GPS location and altitude, pressure, temperature, dew point temperature, and wind velocity, as well as an onboard video camera to document the ambient sky conditions during each aircraft flight (Delene et al. 2019a). GPS data is obtained with an Applanix Position and Orientation System for Airborne Vehicles (model POSAV 310). The pressure is measured with dual static pressure ports located on the fuselage that are connected to a Honeywell static pressure transducer (SN 53166), which is calibrated using a Mensor digital pressure gauge (model 2310). Ambient temperature is measured with a Rosemount total temperature sensor (model 102 deiced), which measures temperatures in a range from -65 to $50{ }^{\circ} \mathrm{C}$. Dew point temperature and relative humidity are derived using the air temperature measurement and water vapor mixing ratio measurements 
made with a Maycomm Research Company Tunable Diode Laser Hygrometer (TDL, model AC19-400). The TDL-derived relative humidity parameter is with respect to water when ambient temperatures are greater than or equal to $0{ }^{\circ} \mathrm{C}$ and is with respect to ice below $0{ }^{\circ} \mathrm{C}$.

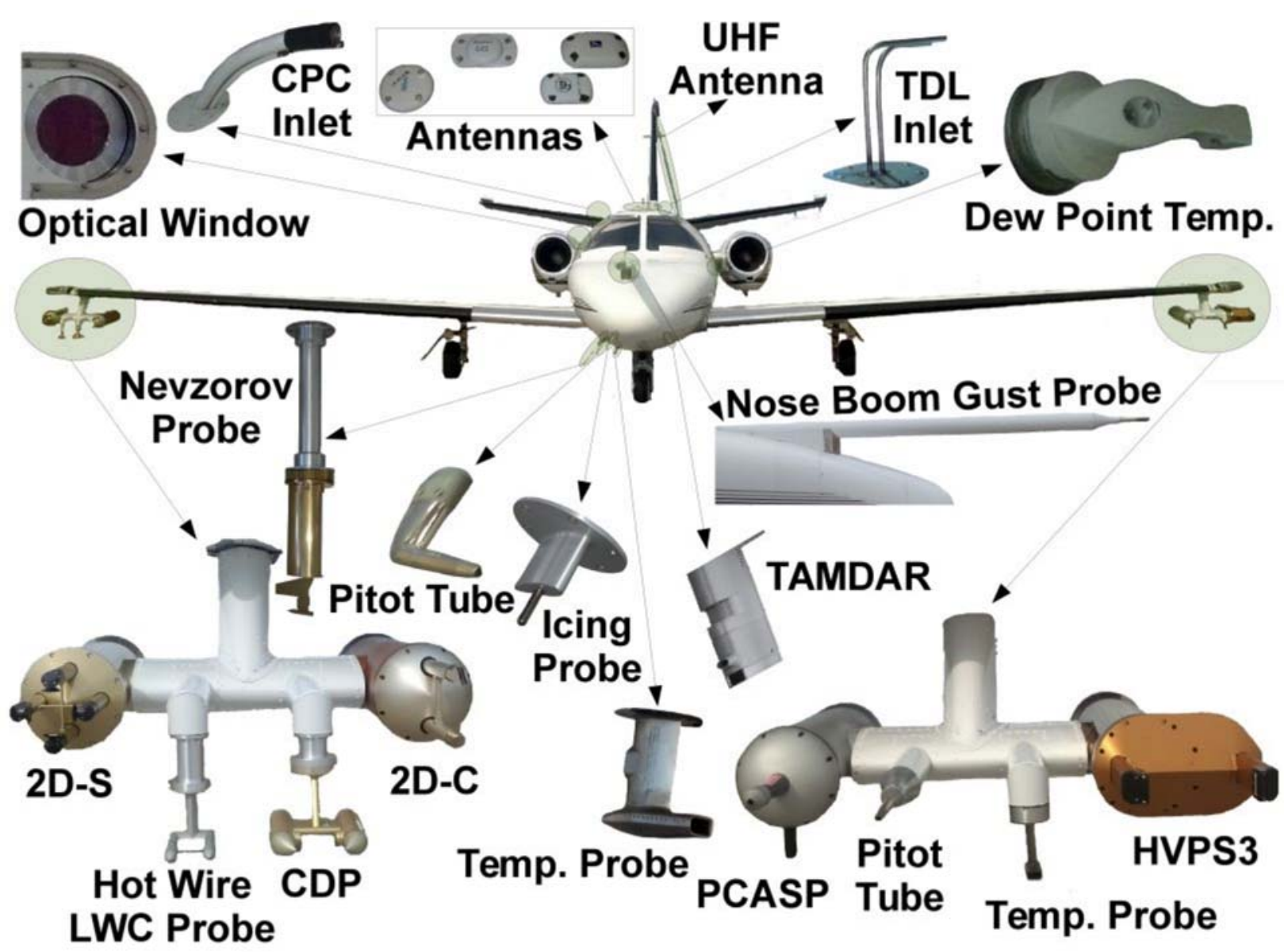

Figure 1. The suite of externally mounted instruments on the Citation Research Aircraft is shown. Cloud physics instruments are the High Volume Particle Spectrometer Version 3 (HVPS3) probe, the Two-Dimensional Cloud (2D-C) probe, the Cloud Droplet Probe (CDP), and the Two-Dimensional Stereographic (2D-S) probe. Aerosol instruments are the Condensation Particle Counter (CPC) in the cabin (air intake labeled) and the Passive Cavity Aerosol Spectrometer Probe (PCASP). Water content instruments are the King Hot Wire Probe ("Hot Wire LWC Probe"), the Nevzorov Water Content Probe ("Nevzorov Probe"), and the Rosemount Ice Detector ("Icing Probe"). Atmospheric state parameters are measured with the Tunable Diode Laser Hygrometer (TDL) in the cabin (air intake labeled), Edgetech Chilled Mirror Dew Point Sensor Probe ("Dew Point Temp.") in the cabin (air intake labeled), the Five-Port Gust Probe ("Nose Boom Gust Probe"), the Tropospheric Airborne Meteorological Data Reporting (TAMDAR) probe, and two temperature probes ("Temp. Probe"). The aircraft includes an ultrahigh frequency (UHF) antenna for long range communication, several GPS antennas, and 
satellite communication antennas. Miscellaneous instruments include an Optical Window for optical ice detectors in the cabin and various Pitot Tubes for measuring the aircraft's air speed.

A Science Engineering Associates (SEA) data acquisition system (model M300) recorded all measurements, except from the 2D-S and HVPS3, in a single binary file. The Airborne Data Processing And Analysis software package (ADPAA) is used to extract and post-process the acquired data (Delene 2011). The current version of ADPAA (Delene et al. 2019b) is used to process the CAPE2015 data set for the analysis presented herein. ADPAA uses various methods and quality assurance procedures to obtain a robust data set for scientific analysis, such as automatically correcting the total temperature measurement for dynamic heating to obtain air temperature. All software used for the data analysis presented in this paper is openly available, follows the ADPAA programing guidelines, and referenced herein to enable reproducibility of the presented work and usage in future projects (Appendix A).

A cloud physics suite of instruments is onboard the Citation Research Aircraft that includes a SkyPhysTech Nevzorov Water Content Probe (CWCM-U2, hereafter referred to as the Nevzorov) cloud water content and two Stratton Park Engineering Company, Inc. (SPEC, Inc.) optical array probes, a Two-Dimensional Stereographic probe (2D-S) and a High Volume Precipitation Spectrometer version 3 (HVPS3), for measuring particle size distributions. The Nevzorov measures both total and liquid water content using two separate heated wires that are maintained at a constant temperature of $125^{\circ} \mathrm{C}$ (Korolev et al. 1998). A direct relation between the rate of evaporative cooling on the heated surfaces and the amount of power required to maintain a constant temperature allows for the calculation of cloud water content. The TWC is measured using a $60^{\circ}$ concave cone ("deep cone") that is maintained at a temperature near the boiling point of water. The liquid water content is measured using a heated wire situated above and heated as much as the TWC sensor. The sensitivity of the Nevzorov is $0.003 \mathrm{~g} \mathrm{~m}^{-3}$ and 
measures total and liquid water content in the range of $0.003-3.0 \mathrm{~g} \mathrm{~m}^{-3}$. The diameter of the sampling area of the TWC sensor is approximately $8 \mathrm{~mm}$. Wind tunnel tests have shown ice particles with a maximum dimension of $<4 \mathrm{~mm}$ are effectively measured by the TWC sensor and larger ice particles (especially with maximum dimension $>10 \mathrm{~mm}$ ) may partially or fully bounce out of the cone before completely melting (Korolev et al. 2013b). The Nevzorov processing within ADPAA accounts for sensor wetting in mixed-phased clouds and dynamically calculates calibration coefficients using a multiple linear regression of static pressure and indicated airspeed to calibrate the water content data on a per-flight basis. An automatic baseline offset determined from out-of-cloud locations using 2D-S particle concentrations is applied to the flight-calibrated water content values so as to correct for clear air drift in the instrument (Delene et al. 2019a).

The 2D-S measures particles asynchronously using two perpendicular lasers to illuminate two separate arrays of 128 photodiodes with each photodiode being $10 \mu \mathrm{m}$ in diameter (Lawson et al. 2006). The HVPS3 measures particles asynchronously using one laser to illuminate an array of 128 photodiodes each $150 \mu \mathrm{m}$ in diameter (Lawson et al. 1993). As particles pass through the laser beams on both the 2D-S and HVPS3, shadow images are cast on the arrays of photodiodes and are separated into bins based on their diameters during data post-processing. The 2D-S and HVPS3 are equipped with anti-shattering tips that minimize particle fragments produced by the impact with the probe from passing within the instrument's sample volume (Korolev et al. 2013a). The two data sets created by the 2D-S are referred to as horizontal and vertical per the orientation of the laser in relation to the horizon (horizontal is parallel with the horizon and vertical is orthogonal). The HVPS3 was mounted horizontally, so its data is inherently horizontal in this study. 
ADPAA provides linkage modules to automatically process 2D-S and HVPS3 data using the System for Optical array probe Data Analysis version 2 software package (SODA2) (Bansemer 2016). The SODA2 processing organizes the particles observed by the 2D-S and HVPS3 into 29 and 28 size bins, respectively. Size bins increase in width with increasing diameter and range from 10 to $2000 \mu \mathrm{m}$ for the 2D-S and $150 \mu \mathrm{m}$ to $3 \mathrm{~cm}$ for the HVPS3. The varying bin widths help to organize similar numbers of particle counts in the different bins. The SODA2 processing is set to reconstruct particles (Heymsfield and Parrish 1978) using the fast circle method if only a portion of a particle is determined to be visible or is larger than the maximum observing size of the probe. Thus, reconstruction processing allows particles larger than the optical array to be sampled. The fast circle method fits the smallest circle around each particle measured by the 2D-S and HVPS3 that encloses them, and the method has been shown to provide the best definition of the maximum dimension of a particle measured by an optical array probe (Wu and McFarquhar 2016). SODA2 also filters out particles observed by the 2D-S and HVPS3 that have both an area ratio less than 0.2 and a diameter larger than $500 \mu \mathrm{m}$. A dynamic filter is applied to remove particles that have short interarrival times (generally less than $0.2 \mathrm{~ms}$ ), which is a signature of particle shattering near the tips of the probes (Korolev et al. 2013a). For additional processing details, see Appendix A and the documentation within the ADPAA and SODA2 software codes (Delene et al. 2019b; Bansemer 2016).

\section{Radar Observations}

The United States Navy owns and operates the MCR, which is located along the eastern coast of Florida, north of the Kennedy Space Center/Cape Canaveral Air Force Station (Schmidt et al. 2019). The MCR is a C-band, dual-polarization, Doppler radar with the capability of switching between two waveforms, a low-resolution beam with an along-range resolution of $37 \mathrm{~m}$ (7.45 
$\mathrm{MHz}$ bandwidth, hereafter referred to as the narrowband beam) and a high-resolution beam with an along-range resolution of $0.546 \mathrm{~m}(500 \mathrm{MHz}$ bandwidth, hereafter referred to as the wideband beam) (Schmidt et al. 2019). The MCR uses linear frequency modulation (LFM) pulse compression to compress both $12.5 \mu$ s narrowband and wideband pulses down to the specified range resolutions. Two separate range windows within each beam are used to focus on specific sections of the beams. The windows can be placed either side-by-side or apart from each other to simultaneously sample different regions along the beam. The beams are circularly polarized which allow for easy tracking of large objects, such as the Citation Research Aircraft, since the sphericity of a target determines the polarization of the return signal and each direction of polarization is received by separate antennae. Receiving each direction of polarization separately improves the ability to detect non-spherical targets (such as aircraft) within precipitation by reducing the amount that echoes from precipitation contribute to the overall power returned (Sauvageot 1992). The unique specifications of the MCR (Table 1) enable detection of individual, readily observable rain drops in the free atmosphere (Schmidt et al. 2012, 2019), which other standard weather radars such as the National Weather Service's Next Generation Weather Radar (NEXRAD) network are not able to do. 
Table 1. Comparison of properties of the Mid-Course Radar (MCR), the University of North Dakota (UND) Weather Surveillance Radar 1974-C (WSR-74C), and the National Weather Service (NWS) Weather Surveillance Radar 1988-D (WSR-88D) systems is shown. The values have been adapted from Schmidt et al. (2019) and Rinehart (2010), with additions from University of North Dakota (2004) and NOAA (2017). The MCR narrowband (NB) and wideband (WB) beam properties are listed separately when appropriate. The calculation of the $50 \mathrm{~km}$ sensitivity of the MCR is described in Appendix B.

\begin{tabular}{|l|c|c|c|}
\hline & MCR & UND WSR-74C & NWS WSR-88D \\
\hline Antenna Diameter (m) & 15.24 & 3.66 & 8.53 \\
\hline Beamwidth (degrees) & 0.22 & 0.99 & 1.0 \\
\hline Peak Power (MW) & 3.0 & 0.25 & 0.7 \\
\hline Frequency (GHz) & $5.405-5.895$ & 5.6 & $2.7-3.0$ \\
\hline Pulse Repetition Frequency (Hz) & $\begin{array}{c}160 \text { (NB and } \\
\text { WB) or 320 }\end{array}$ & $250-1200$ & $318-1304,318-452$ \\
\hline Pulse Length ( $\boldsymbol{\mu s )}$ & 12.5 & 0.6 or 2.0 & 1.57 or 4.5 \\
\hline Transmitter Polarization & Circular, right & $\begin{array}{c}\text { Linear, horizontal } \\
\text { and vertical }\end{array}$ & $\begin{array}{c}\text { Linear, horizontal } \\
\text { and vertical }\end{array}$ \\
\hline Receiver Polarization & Circular, right & $\begin{array}{c}\text { Linear, horizontal } \\
\text { and vertical }\end{array}$ & $\begin{array}{c}\text { Linear, horizontal } \\
\text { and vertical }\end{array}$ \\
\hline Maximum Range Resolution (m) & 0.546 & 90 & 250 \\
\hline Minimum Range Resolution (m) & 37 & 300 & 250 \\
\hline Sensitivity at 50 km Range (dBZ) & $\begin{array}{c}-36(\mathrm{NB}), \\
-18(\mathrm{WB})\end{array}$ & -8.0 & -10.0 \\
\hline
\end{tabular}

Two MCR radar scanning strategies are used during the CAPE2015 field project, a vertical stare and a specialized scan that tracks the aircraft in real-time. The vertical stare scanning strategy is a fixed scan whereby the antenna of the MCR is oriented approximately $90^{\circ}$ from the horizon while the Citation Research Aircraft completes horizontal legs of approximately $30 \mathrm{~km}$ in length at different altitudes directly over the MCR (Gapp et al. 2019). Wideband pulse volumes at the maximum range of the aircraft $(12 \mathrm{~km})$ are as fine as $494 \mathrm{~m}^{3}$ (Schmidt et al. 2014). For perspective, the smallest box that completely encases the Citation Research Aircraft would have an approximate volume of $1,050 \mathrm{~m}^{3}$. For the aircraft tracking scanning strategy, position information from the Citation Research Aircraft is downlinked to the MCR using a 465 $\mathrm{MHz}$ VHF antenna system. The downlinked information provides the general aircraft location 
which enables the MCR to obtain a lock on the large return from and subsequently track the aircraft. Wideband pulse volumes during the analyzed tracking scan cases range from 2,320 $\mathrm{m}^{3}$ to $5,770 \mathrm{~m}^{3}$ (Schmidt et al. 2014).

The aircraft tracking scanning strategy produces a nearly co-located data set between the aircraft and the MCR. In order for the MCR to track the aircraft, the narrowband beam is set to follow the large return signal created by the aircraft. The aircraft tracking creates a "stripe" of contamination throughout the range window (Figure 2). Due in part to the $12.5 \mu$ s pulse length, the effects of the range side lobes due to pulse compression are enhanced; therefore, the contamination covers an along-beam distance of approximately $3.5 \mathrm{~km}$ which renders data within an along-beam range of $3.5 \mathrm{~km}$ surrounding the aircraft unusable. Hence, the wideband data is the focus of this study and the narrowband data is not further discussed. A pulse length of $1 \mu \mathrm{s}$ is planned for an upcoming field project to lessen the size of the contamination "stripe" within the narrowband data. 


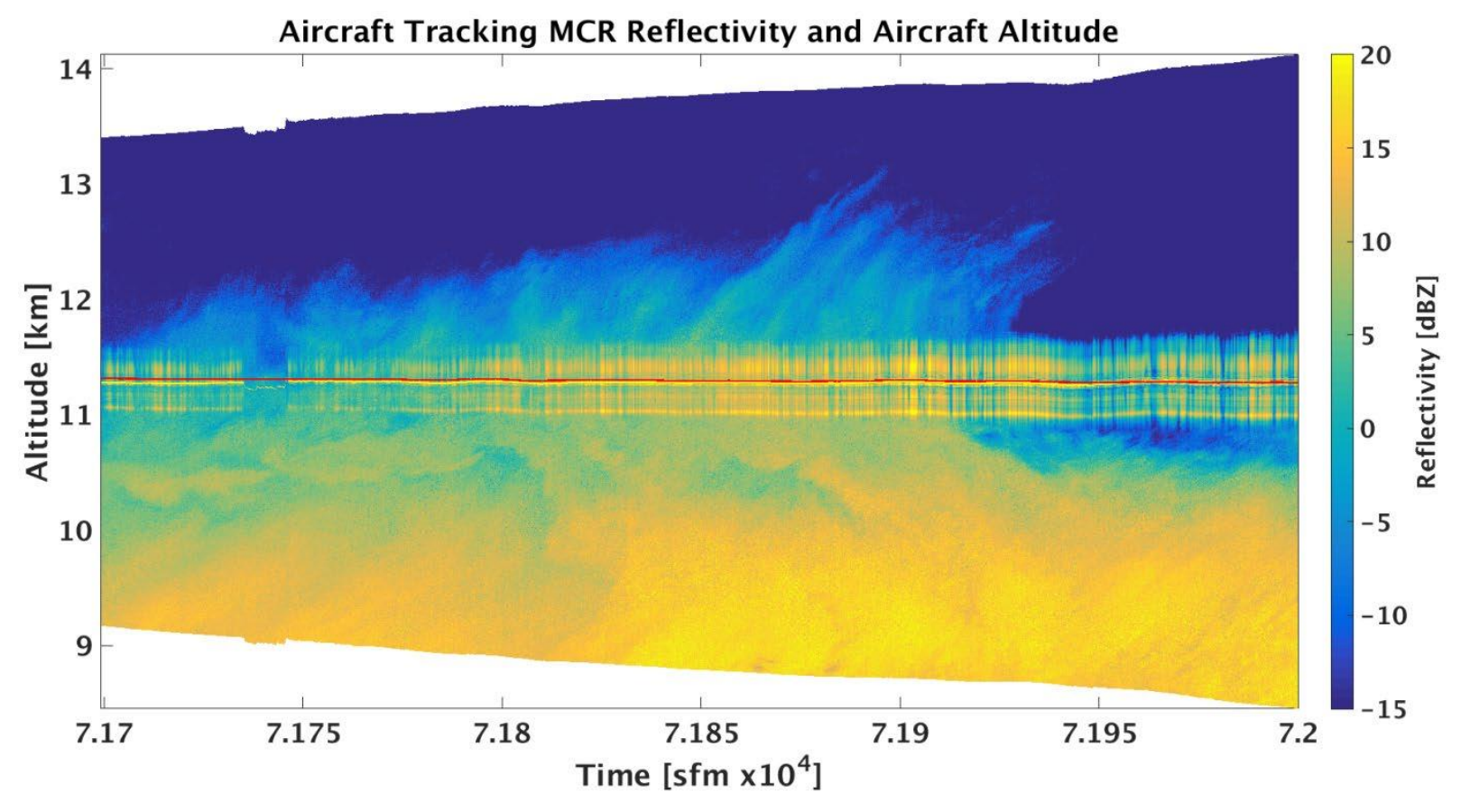

Figure 2. The radar reflectivity factor from the narrowband beam of the MCR (shading) and the height of the aircraft (red line) are shown during a segment of a research flight on 01 August 2015. The "stripe" of high radar reflectivity factor between 11-11.5 km (approximately $3.5 \mathrm{~km}$ in along-beam range) is contamination from the high reflectivity returns caused by the Citation Research Aircraft. Altitude (AGL) of the beam at each range gate (y-axis) is derived per pulse using the distance at each range gate and the elevation angle. The altitude calculations are based on the 4/3 Earth's radius model [Equation 2.28b from Doviak and Zrnić (1984)]. Note the range to the aircraft is constantly changing since the MCR is tracking the aircraft during this period, but the range and altitude are plotted using only the first shown pulse's range and altitude.

\section{Aircraft and Radar Data Comparisons}

Two radar reflectivity data sets are discussed in this paper: an observed radar reflectivity factor data set from the MCR (hereafter referred to as the MCR reflectivity) and a derived equivalent radar reflectivity factor data set (hereafter referred to as the derived reflectivity or $Z_{e}$ ) obtained from the microphysical probes onboard the Citation Research Aircraft (specifically the 2D-S, HVPS3, and Nevzorov). Processed MCR radar cross-section (RCS) data and the derived reflectivity data are married via Matlab programs (Appendix A). The range gates are calculated using the RCS data and the aircraft as a reference range. The data are subset by range to a userdefined depth and averaged by pulse to a user-defined setting if required. The derived 
reflectivity is subset by time to fit within the starting and ending times of the MCR data. Subsetting the MCR data by range and time and averaging by pulse makes the data analysis faster and easier since the original data files are very large ( $>20 \mathrm{~GB}$ per file) and hence require large amounts of computer resources to process.

Derived reflectivity is directly calculated from the merged particle spectrum of effective liquid particle sizes and concentrations from the 2D-S and HVPS3 probes. The measured particle spectra are used instead of fitting the data to a gamma or Poisson distribution in order to make the concurrent in-situ and remote observations more directly comparable to each other. Even though the measured particle spectra induce additional noise in the derived data, the uncertainty analysis is simplified since no additional uncertainty is added and instrument uncertainties alone can be propagated through the calculations (unlike fitting the data where additional uncertainty is introduced into the data derived from it). The merged spectrum is obtained by using horizontal 2D-S data below $1,000 \mu \mathrm{m}$ and HVPS3 data above $1,000 \mu \mathrm{m}$. The HVPS3 data is inherently horizontal since it was mounted horizontally and only has one orientation measurement. Merging the probe spectra in this way eliminates 2D-S reconstructed particles from the distribution and replaces them with those measured by the HVPS3. No particles are observed above $1.5 \mathrm{~cm}$ in diameter, so processing HVPS3 data without particle reconstruction is not necessary since full reconstruction begins at $1.92 \mathrm{~cm}$. Particle sizes less than $105 \mu \mathrm{m}$ in diameter are disregarded from the derived reflectivity calculation due to the problematic nature of artifacts from fragments of particles near the edge of the depth of field of the probe (O'Shea et al. 2019). These artifacts appear as individual particles only a few pixels in size which can erroneously increase the particle concentrations within smaller size bins and adversely affect the overall particle size distribution. Additionally, the smaller size particles do 
not contribute significantly to the derived reflectivity since radar reflectivity uses the sixth moment of the diameter (see Equation 4).

Effective liquid particle sizes $\left(d_{l}\right)$ are derived from the combined particle size spectrum and an effective density of the particles by setting the mass of water equal to the mass of the particle. For each size bin in the merged particle size spectrum, the effective liquid particle size is found using the equation:

$$
d_{l}=\sqrt[3]{\frac{6 V \rho_{e}}{\pi \rho_{w}}}
$$

where $V$ is the volume of the size bin, $\rho_{e}$ is the effective particle density, and $\rho_{w}$ is the density of water. The average (bulk) effective liquid particle size is found by summing $d_{l}$ across the merged particle size spectrum and dividing the sum by the number of size bins that contain particles per time step. The average is calculated in this way because the number of size bins within the merged particle size spectrum that contain particles can change per time step. The effective particle density (Heymsfield et al. 2004) accounts for the presence of non-solid ice particles caused by air spaces within the particles and is calculated by

$$
\rho_{e}=\frac{m_{N e v}}{V_{T}}
$$

where $m_{N e v}$ is the total particle mass (from all particles within the particle size distribution) obtained from the total water content from the Nevzorov probe and $V_{T}$ is the total particle volume obtained from the particle spectrum using:

$$
V_{T}=\sum_{i} \frac{\pi}{6} N_{i} D_{i}^{3}
$$

where $N_{i}$ and $D_{i}$ are the particle concentration and the diameter of each size bin, respectively. The derived radar reflectivity factor $\left(\mathrm{mm}^{6} \mathrm{~m}^{-3}\right)$ is calculated by 


$$
z=\sum_{i} N_{i} d_{l}^{6}
$$

where $N_{i}$ and $d_{l}$ are the particle concentration and the effective liquid particle size per size bin, respectively. Differences between the dielectric factors of water and ice (Smith 1984) are taken into account using a ratio of $0.224\left(z_{e}=0.224 z\right)$, and $z_{e}$ is converted to logarithmic units $\left(Z_{e}[d B Z]=10 \log _{10} Z_{e}\right)$ for comparison with the reflectivity from the MCR's observation.

Uncertainties for $z$ in Equation 4 are determined using only the uncertainty in the number concentration. Uncertainties from both the Nevzorov TWC measurements and the derivations of effective liquid particle size are not included. The uncertainty in the Nevzorov measurements within the effective particle density and effective liquid particle size derivations is associated with out-of-cloud drift and is corrected within the data processing; therefore, the uncertainty of the Nevzorov measurements should be negligible. The uncertainty within the particle concentration measurements is obtained using Poisson Counting Statistics where the channel counts are the mean of a Poisson distribution and the uncertainty is taken as the standard deviation, which is given by the square root of the number of particles; therefore, the relative error is:

$$
\epsilon_{N}=n^{-1 / 2}
$$

where $n$ is the number of particles in a given size bin (Horvath et al. 1990). Uncertainty in measurements of the particle concentration of a given size bin, $\delta N$, is calculated by multiplying $\epsilon_{N}$ by the particle concentration of a given size bin since the concentration relative uncertainty is the same as the relative uncertainty in particle counts. Absolute uncertainties in $z, \delta z$, are given per bin by:

$$
\delta z=\frac{\partial z}{\partial N} \delta N
$$


Uncertainty relative to the radar reflectivity factor in a given bin $\left(\epsilon_{z}=\delta z / z\right)$ is summed over all bins to give the total uncertainty of $z$.

For comparison with the derived reflectivity, the MCR reflectivity is averaged over a set column of ranges surrounding the aircraft by converting the MCR reflectivity to linear units $\left(\mathrm{mm}^{6} \mathrm{~m}^{-3}=10^{d B Z / 10}\right)$, averaging the data, and converting the average back to logarithmic units. Times when the aircraft is in clear air (Nevzorov TWC measurements are not above 0.005 $\mathrm{g} \mathrm{m}^{-3}$ ) are excluded in the comparisons between the derived and MCR data sets. Level flight legs of in-cloud data are used for the comparison between derived and MCR reflectivity values to minimize natural cloud variability. The time segment used for the comparison should be short enough to capture changes in reflectivity due to natural variability; however, time segments should be long enough such that uncertainties (e.g. due to counting statistics) are small enough to enable a determination if there are systematic differences between the aircraft and radar observations. Comparisons are made using 1 second averaged data which captures the natural viability within the atmosphere and 10 second averaged data to lower the uncertainties enough to allow for the evaluation of systematic differences between the in-situ and remote data. 


\section{DATA ANALYSIS}

The CAPE2015 field project focused on sampling afternoon thunderstorms in northeastern Florida during late July and early August. Four flights measured TWC and particle size distributions of cirrus clouds from thunderstorm anvils at temperatures below $-30^{\circ} \mathrm{C}$ (Table 2). Together, the four flights provide approximately 4.5 hours of measurements from 7.7 to $10.3 \mathrm{~km}$ over a temperature range of -30 to $-47^{\circ} \mathrm{C}$. Approximately $27 \%$ of the times during flights from 30 July to 02 August have in-cloud measurements during level flight and temperatures at or below $-30.0{ }^{\circ} \mathrm{C}$. The other $73 \%$ of the time, the aircraft is turning and/or changing altitude which is typically done in clear air. The data set has been quality assured by manually reviewing the measurements and invalid data is excluded from the analysis. For example, a portion of the 02 August flight is excluded due to a stuck bit issue on the 2D-S probe.

Table 2. Shown are the CAPE2015 field project in-cloud segments with level flight and temperatures below $-30{ }^{\circ} \mathrm{C}$. The start and end times of each segment are in Universal Coordinated Time (UTC) seconds from midnight on the day of the flight (sfm). The minimum and maximum altitudes $(\mathrm{m})$ and temperatures $\left({ }^{\circ} \mathrm{C}\right)$ during each segment are given. The last column provides the amount of each segment where the temperature is at or below $-30^{\circ} \mathrm{C}$, the Nevzorov TWC is greater than $0.005 \mathrm{~g} \mathrm{~m}^{-3}$ (in-cloud), and the aircraft is level (pitch between $2.5^{\circ}$ and $4.5^{\circ}$ ).

\begin{tabular}{|c|c|c|c|c|c|}
\hline Date & Start & End & Min/Max Altitude & Min/Max Temperature & Points/Percent \\
\hline Y/M/D & sfm & sfm & $\mathrm{m}$ & ${ }^{\circ} \mathrm{C}$ & $\# / \%$ \\
\hline $2015 / 07 / 30$ & 65,035 & 65,168 & $9,680 / 9,703$ & $-30.8 /-30.0$ & $133 / 100.0$ \\
\hline $2015 / 07 / 31$ & 68,466 & 74,812 & $9,526 / 10,019$ & $-34.2 /-30.1$ & $1,760 / 27.7$ \\
\hline $2015 / 08 / 01$ & 68,624 & 76,554 & $7,726 / 10,019$ & $-47.2 /-30.2$ & $2,036 / 25.7$ \\
\hline $2015 / 08 / 02$ & 71,606 & 73,370 & $9,988 / 10,337$ & $-36.7 /-32.7$ & $467 / 26.5$ \\
\hline
\end{tabular}

A variety of conditions are sampled, ranging from anvil edges with low saturations with respect to ice (measured by TDL), to the middle of the anvil with high particle concentration and relatively large particles. The constant altitude flight segments (Table 2) are broken into $60 \mathrm{~s}$ 
segments where the particle concentrations and sizes have relatively small variability (Table 3 and Figure 3). Particle concentrations are generally low $\left(<0.1 \# \mathrm{~cm}^{-3}\right)$, and variability is low as indicated by the standard deviations being below the means of particle concentration and median volume diameter.

Table 3. Analyzed time segments from four flights in Table 2 are shown. The start and end times of each segment are in Universal Coordinated Time (UTC) seconds from midnight on the day of the flight (sfm). The mean and standard deviation of the temperature, total particle concentration greater than $105 \mu \mathrm{m}$ in diameter, and median volume diameter (MVD) greater than $105 \mu \mathrm{m}$ in diameter for each time segment are given.

\begin{tabular}{|c|c|c|c|c|c|}
\hline Date & Start & End & Temperature & Concentration & MVD \\
\hline Y/M/D & sfm & $\mathrm{sfm}$ & ${ }^{\circ} \mathrm{C}$ & $\#_{\mathrm{cm}^{-3}}$ & $\mu \mathrm{m}$ \\
\hline $2015 / 07 / 30$ & 65,040 & 65,100 & $-30.0 \pm 0.1$ & $0.04 \pm 0.03$ & $377 \pm 26$ \\
\hline & 65,100 & 65,160 & $-30.2 \pm 0.1$ & $0.03 \pm 0.02$ & $269 \pm 54$ \\
\hline $2015 / 07 / 31$ & 69,780 & 69,840 & $-33.8 \pm 0.1$ & $0.03 \pm 0.01$ & $224 \pm 13$ \\
\hline & 71,400 & 71,460 & $-33.3 \pm 0.1$ & $0.19 \pm 0.09$ & $235 \pm 68$ \\
\hline & 72,570 & 72,630 & $-33.6 \pm 0.2$ & $0.03 \pm 0.02$ & $296 \pm 62$ \\
\hline & 73,960 & 74,020 & $-33.0 \pm 0.1$ & $0.06 \pm 0.04$ & $223 \pm 29$ \\
\hline $2015 / 08 / 01$ & 71,100 & 71,160 & $-43.0 \pm 0.2$ & $0.64 \pm 0.46$ & $384 \pm 139$ \\
\hline & 72,510 & 72,570 & $-45.6 \pm 0.2$ & $0.54 \pm 0.13$ & $456 \pm 88$ \\
\hline & 74,680 & 74,740 & $-37.9 \pm 0.4$ & $0.09 \pm 0.07$ & $292 \pm 66$ \\
\hline & 75,330 & 75,390 & $-37.7 \pm 0.1$ & $0.08 \pm 0.05$ & $245 \pm 80$ \\
\hline $2015 / 08 / 02$ & 72,470 & 72,530 & $-33.4 \pm 0.3$ & $1.0 \pm 1.5$ & $436 \pm 171$ \\
\hline & 72,840 & 72,900 & $-33.9 \pm 0.1$ & $8.1 \pm 5.4$ & $1,276 \pm 256$ \\
\hline & 72,950 & 73,010 & $-33.8 \pm 0.2$ & $10.0 \pm 3.0$ & $994 \pm 106$ \\
\hline & 73,050 & 73,110 & $-33.0 \pm 0.2$ & $9.8 \pm 2.3$ & $736 \pm 53$ \\
\hline
\end{tabular}


a)

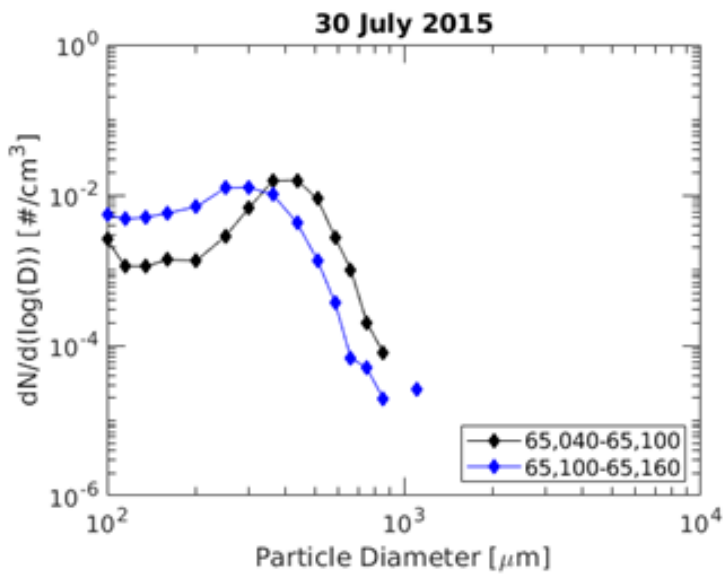

c)

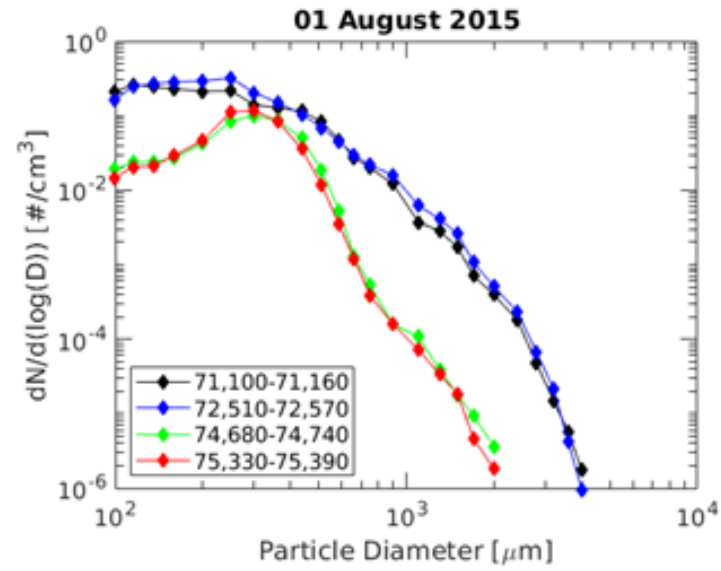

b)

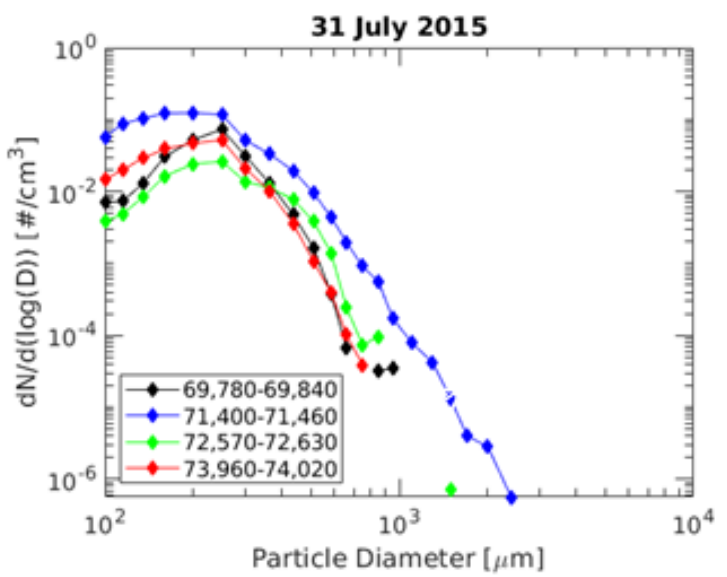

d)

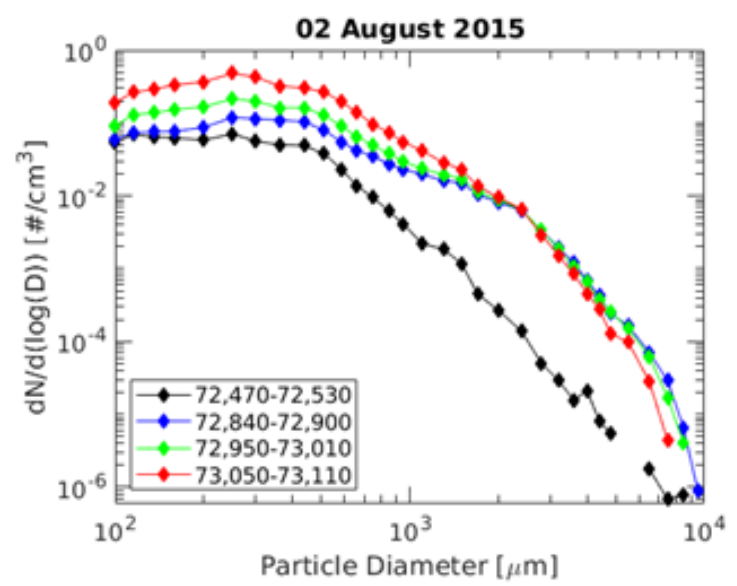

Figure 3. Merged particle size spectra from the 2D-S and HVPS3 probes are shown for four aircraft flights. The legend times are in Universal Coordinated Time (UTC) seconds from midnight on the day the flight started ( $\mathrm{sfm})$. The legends give the 60 second time periods analyzed from within the segments given in Table 3. The particle concentrations are normalized by the log of the size bin created during data post-processing, and the diamonds are the midpoints of the size bins. Discontinuities in the lines are the result of $0 \mathrm{\#} \mathrm{cm}^{-3}$ concentrations for a size bin.

\section{Effective Particle Density and Size}

Effective particle density plays an important role in deriving equivalent radar reflectivity factor. Deriving effective particle density uses a solid, spherical ice particle (absent of air pockets) calculated with Equation 2 to obtain a spherical particle with a density (including air pockets) equivalent to the atmospheric particle. The effective particle densities per median volume diameter calculated for the times in Table 2 show a negative exponential slope in the 
data (Figure 4). The negative exponential slope of the best-fit line is due to larger ice particles having a lower ice density because more pockets of air can and usually do exist within them. The low density, large particles are akin to fluffy snow consisting of larger snowflakes with more air within each snow flake as compared to the smaller, denser snowflakes commonly found in wet snow. No relationship exists with the 30 July data, and a broad negative exponential relationship exists within the rest of the data and especially with 02 August data greater than $\sim 400 \mu \mathrm{m}$.

The CAPE2015 median volume diameter $\left(D_{v}\right)$-effective particle density $\left(\rho_{e}\right.$, Equation 2$)$ relationship using one second-averaged $D_{v}$ and corresponding one second-averaged $\rho_{e}$ are given as $\rho_{e}=a D_{v}{ }^{b}$, where $a=0.00346 \pm 0.00108$ and $b=-1.03 \pm 0.0820$. The range in coefficients represents a $95 \%$ confidence interval whereby the power law line of best fit (solid black line) lies within the upper and lower uncertainty bounds (dashed lines) in Figure 4. The confidence interval represents a range between $0.35 \%$ and $19.0 \%$ uncertainty from the mean values of the coefficients at $100 \mu \mathrm{m}(0.01 \mathrm{~cm})$ and $3 \mathrm{~mm}(0.3 \mathrm{~cm})$, respectively. The $95 \%$ confidence interval also represents an $11.6 \%$ and $56.6 \%$ difference between values on the upper and lower bounds of the confidence interval at $100 \mu \mathrm{m}$ and $3 \mathrm{~mm}$, respectively. The high variability within the confidence interval is due to the $1 \mathrm{~Hz}$ in-situ measurements (each dot in Figure 4) including many sizes and types of particles. The inclusion of a greater variety of particle sizes and types per second also allows for a greater variety in particle density; therefore, large outliers exist and are included in the line of best fit. The outliers should in the future be filtered out and excluded from the regression calculation in order to calculate a better fit to the data. 


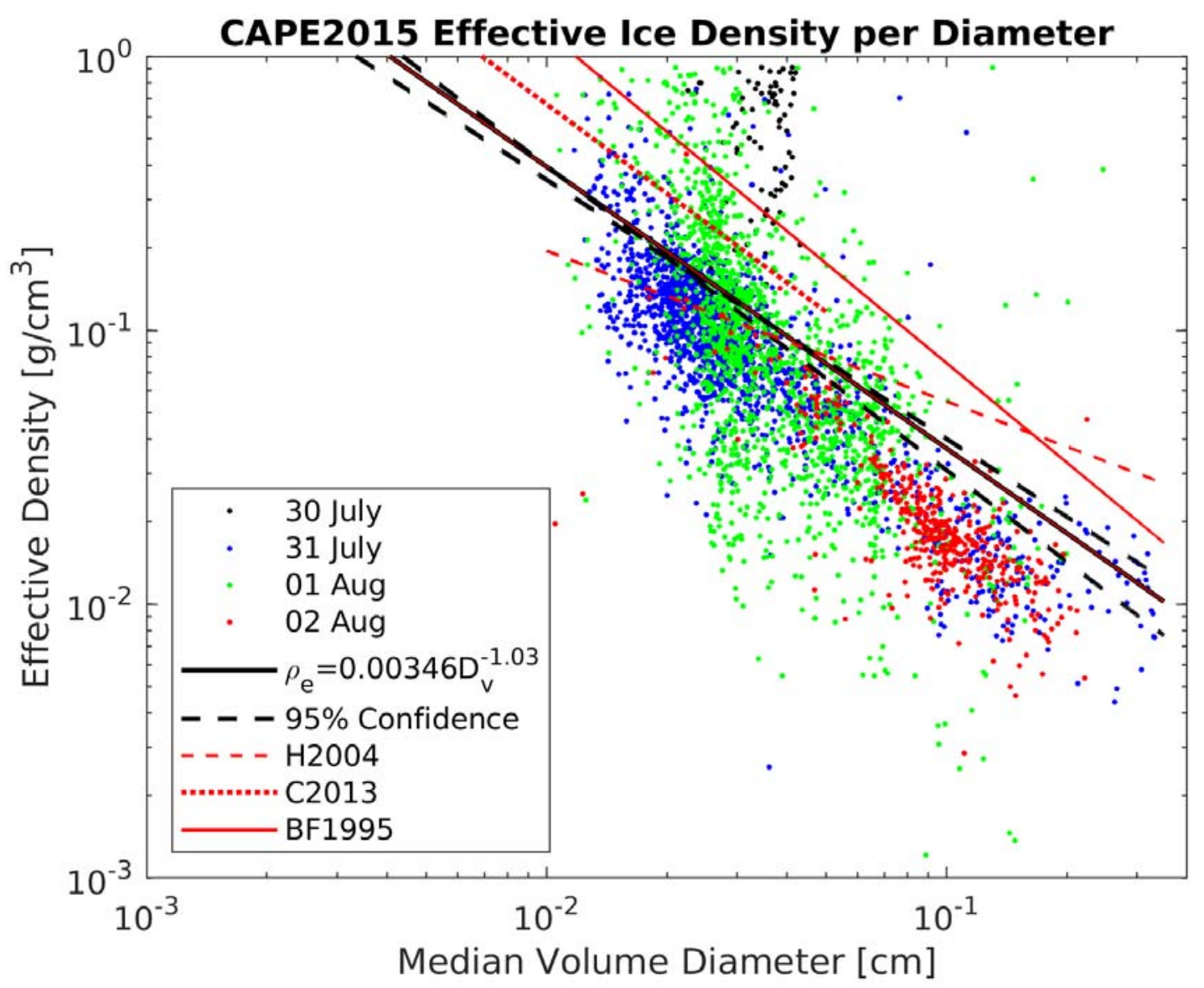

Figure 4. The effective particle densities ( $\rho_{e}$, Equation 2$)$ per median volume diameter $\left(D_{v}\right)$ are shown for the four CAPE2015 field project flights (colored dots) outlined in Table 2. Each data point is an average over $1 \mathrm{~s}$. The line of best fit via a power law regression (solid black line) and the upper and lower bounds of the $95 \%$ confidence interval (dashed black lines) are discussed in the text. The red lines show relationships reported in previous studies. The dashed red line (H2004) represents the $D-\rho_{e}$ relationship of convective cases during CRYSTAL-FACE from Heymsfield et al. (2004). The dotted line (C2013) and dash-dotted line (BF1995) use massdimensional relationships from Cotton et al. (2013) and Brown and Francis (1995), respectively, to derive the $\rho_{e}$ values from the reported mass-dimensional relationships for the times of analysis described in Table 2.

The density-diameter relationships from previous studies agree with the best-fit relationship of effective density data from the CAPE2015 field project. Heymsfield et al. (2004) found a relationship between the median mass diameter, $D_{m}$, from a gamma-distributed particle size distribution and effective ice particle density of $\overline{\rho_{e}}=0.01548 D_{m}{ }^{-0.55}$ for convective cases during CRYSTAL-FACE. This study, however, incorporates data from a limited vertical extent 
and temperature range as compared to previous studies. For example, Heymsfield et al. (2004) used 7 hours of measurements from CRYSTAL-FACE spanning $10 \mathrm{~km}$ in altitude in the temperature range from -20 to $-60^{\circ} \mathrm{C}$, whereas this study utilizes approximately 1.2 hours of data spanning $3 \mathrm{~km}$ in altitude with temperatures ranging from -30 to $-47^{\circ} \mathrm{C}$. Most effective densities at median volume diameters greater than approximately $400 \mu \mathrm{m}$ are lower than those reported in previous research, possibly due to larger particles being observed on average during the CAPE2015 field project than those reported in previous studies.

The effective liquid particle size (Equation 1) is of interest to the U.S. Navy sponsor. Figure 5 shows the variability in the distribution of LEDs throughout the analysis times (Table 2). A bimodal distribution exists with peaks at approximately 200 and $750 \mu \mathrm{m}$ which seems to stem from different types or habits of particles observed. The larger mode (peak near $750 \mu \mathrm{m}$ ) seems to stem from aggregates whereas the smaller mode (peak near $200 \mu \mathrm{m}$ ) seems to come from single crystals. Much of the particles observed on 02 August are aggregates whereas particles observed on 30 July are mainly single crystals. A mix between large and small mode particles is observed on both 31 July and 01 August. 


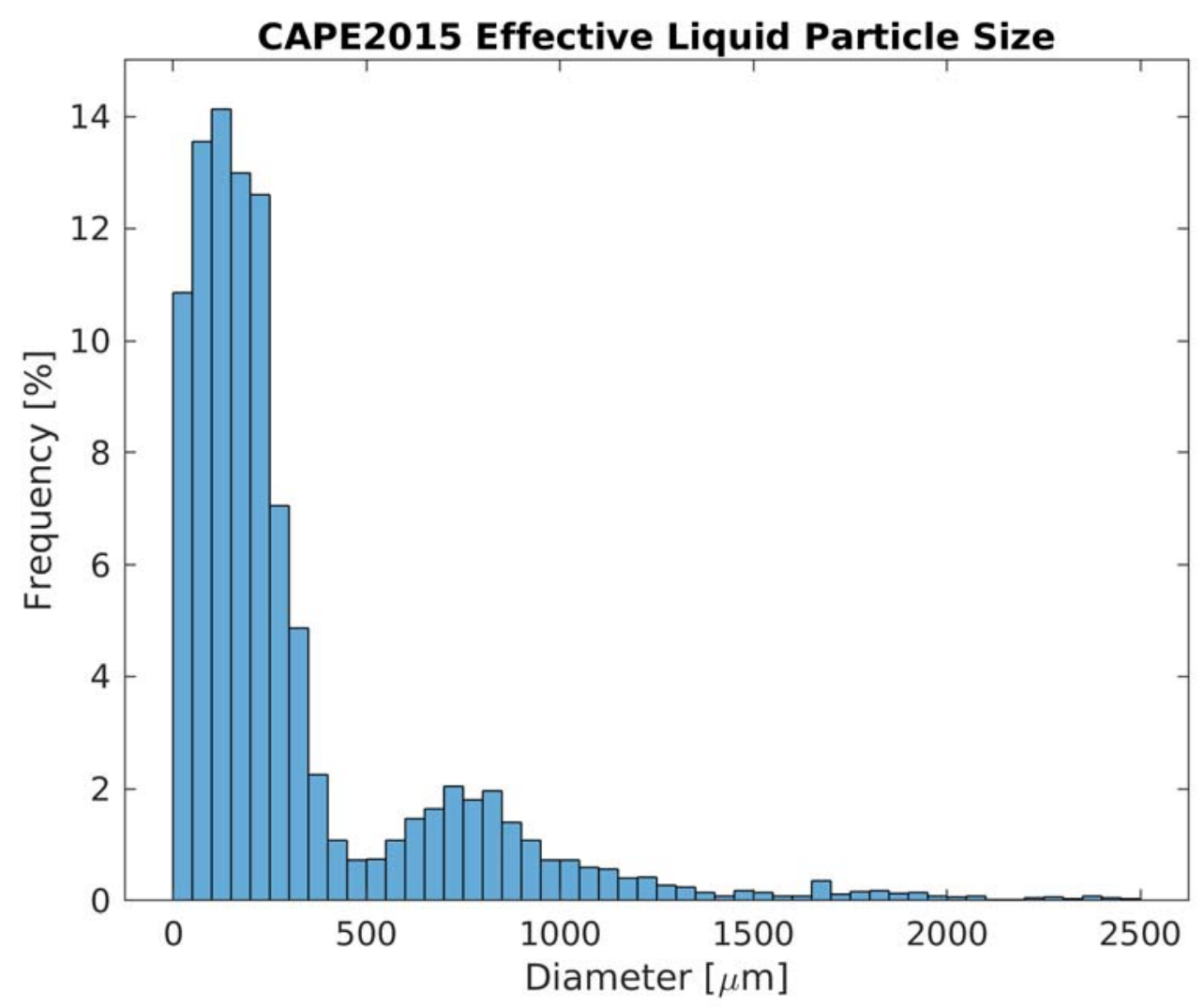

Figure 5. The frequency distribution of $1 \mathrm{~Hz}$ effective liquid particle sizes (Equation 1) is shown for the times described in Table 2 . Note that $89.2 \%$ of the liquid-equivalent diameters are above $50 \mu \mathrm{m}$ in diameter.

\section{AUGUST 2015 CASE STUDY}

On 01 August 2015, the MCR tracked the aircraft for 34 minutes. The aircraft tracking radar data (AC) is divided into four roughly equal segments for ease of transferring and postprocessing the files. Each time interval (radar data file) is labelled sequentially based on its chronological order during the field project (e.g. AC13 is the thirteenth aircraft tracking MCR data file during the CAPE2015 field project). Analyses and comparisons are done only for times that are in-cloud, which is based on 2D-S and Nevzorov probes being above the background outof-cloud limits of $2000 \mathrm{H} \mathrm{m}^{-3}$ and $0.005 \mathrm{~g} \mathrm{~m}^{-3}$, respectively. The cases AC13-AC16 presented herein are in-cloud observations obtained near the top of thunderstorm anvils during constantaltitude flight legs. 
Convection stemming from an upper-level low near the Florida Panhandle on 01 August 2015 produced a broad line of heavy rain that stretched northeast to southwest and moved directly over the MCR. Visible satellite imagery shows a transition from a pre-flight cumuliform cloud environment with an abundance of supercooled liquid water (Figure $7 \mathrm{a}$ ) to a post-flight environment with icy cirrus clouds as the cloud tops glaciated (Figure 7b). The aircraft took off from the Space Coast Regional Airport (KTIX) after the leading line of convection passed (approximately 18:30 UTC) and landed at approximately 21:40 UTC. Anvil tops from 33,000 to 38,000 ft (11.3-11.6 km) MSL were measured with in-situ probes for over 2 hours. The measurements were taken away from areas of strong convection during the aircraft tracking cases (Figure 8). The cross-sections of Melbourne Weather Forecast Office (KMLB) radar returns (Figure 9) indicate that neither the sensitivity nor the resolution is high enough to resolve the cirrus clouds above $33,000 \mathrm{ft}(11.3 \mathrm{~km})$. The low-resolution data from the second-nearest National Weather Service radar located at the Tampa Bay Area Weather Forecast Office (not shown) show no clouds exist at the aircraft altitude. The higher sensitivity and resolution of the MCR (Table 1) enables the cirrus clouds to be measured.

Additionally, the MCR is able to track the aircraft in real-time to obtain the concurrent measurements used in this study. The in-cloud segments during which the MCR tracked the aircraft reached horizontal lengths of approximately 10 to $40 \mathrm{~km}$ (Figure 6). The best method of tracking the aircraft with the MCR is found to be when the aircraft is flying perpendicular to the beam at a tangent to a radial rather than parallel to the beam. Flight paths that are more parallel to the beam can become more contaminated by the aircraft. The range of the aircraft from the MCR is also important since the beam travels a longer distance at a lower elevation angle through atmosphere and can interact with more hydrometeors than at shorter ranges. Since 
tracking case $\mathrm{AC} 14$ is at the largest range from and lowest elevation angle to the MCR, it could be most susceptible to beam attenuation.

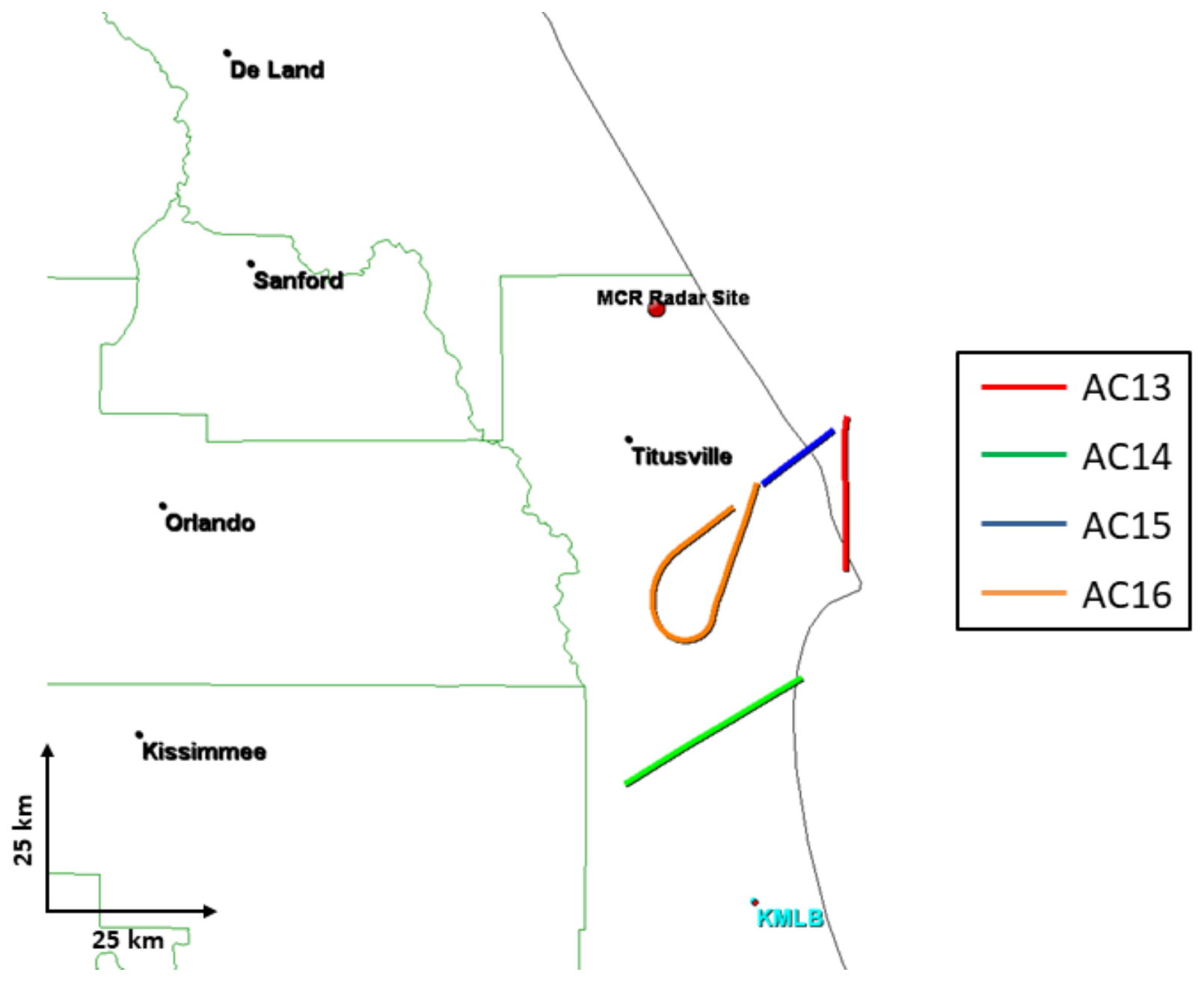

Figure 6. The four in-cloud flight segments during which the aircraft was tracked in real-time by the MCR on 01 August 2015 are shown. The aircraft flight segment times in Universal Coordinated Time (UTC) seconds from midnight on the day of the flight (sfm) are: 71,15471,277 sfm (AC13, red line); 71,717-71,903 sfm (AC14, green line); 72,425-72,500 sfm (AC15, blue line); and 72,530-72,839 sfm (AC16, orange line). 

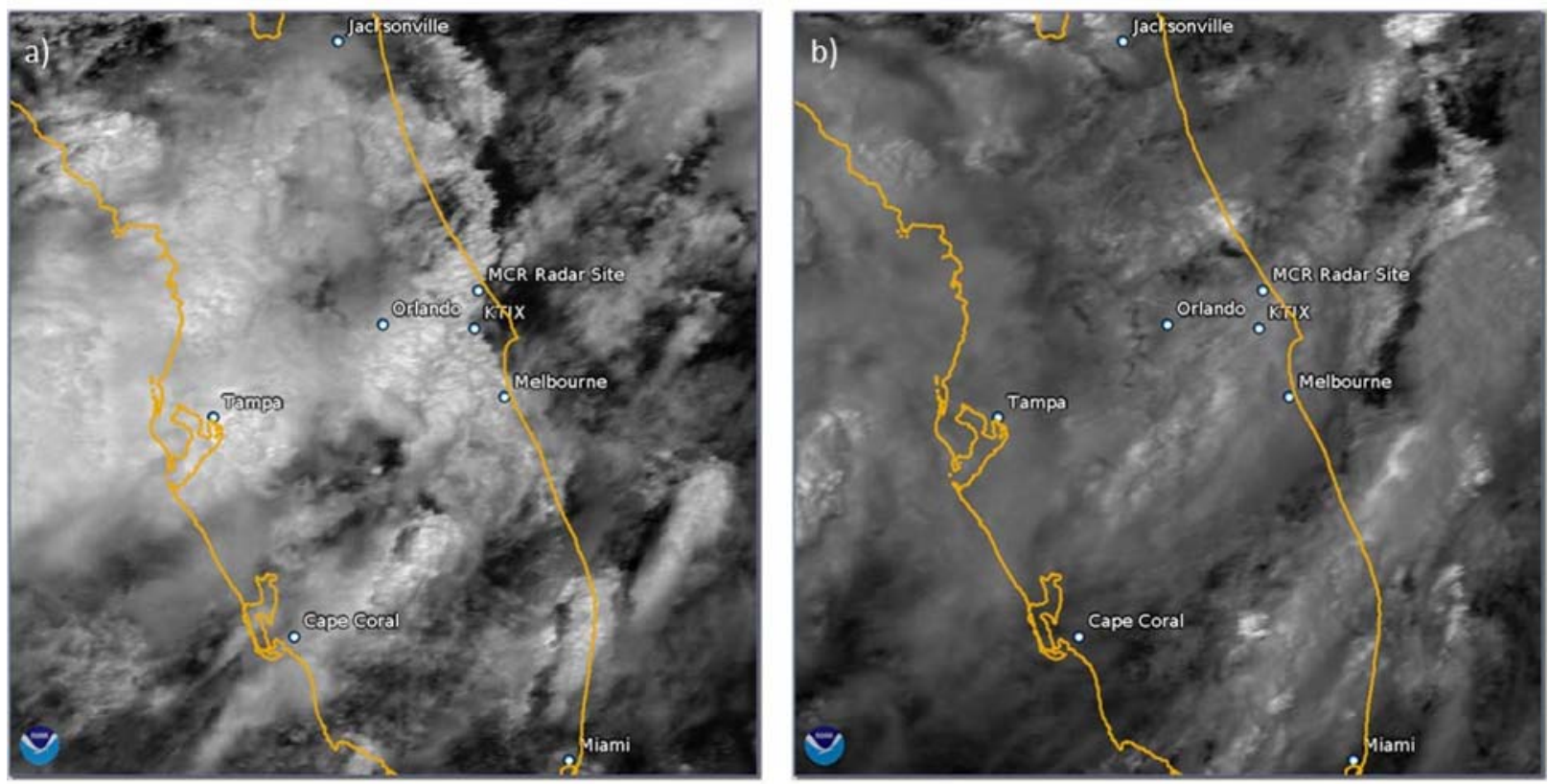

Figure 7. Visible satellite images from GOES15 on 01 August 2015 in Universal Coordinated Time (UTC) at 18:00 UTC (a) and 21:00 UTC (b) are shown. The locations of the MCR radar, the Space Coast Regional Airport (KTIX, home-base for flight operations), and select cities are labeled.
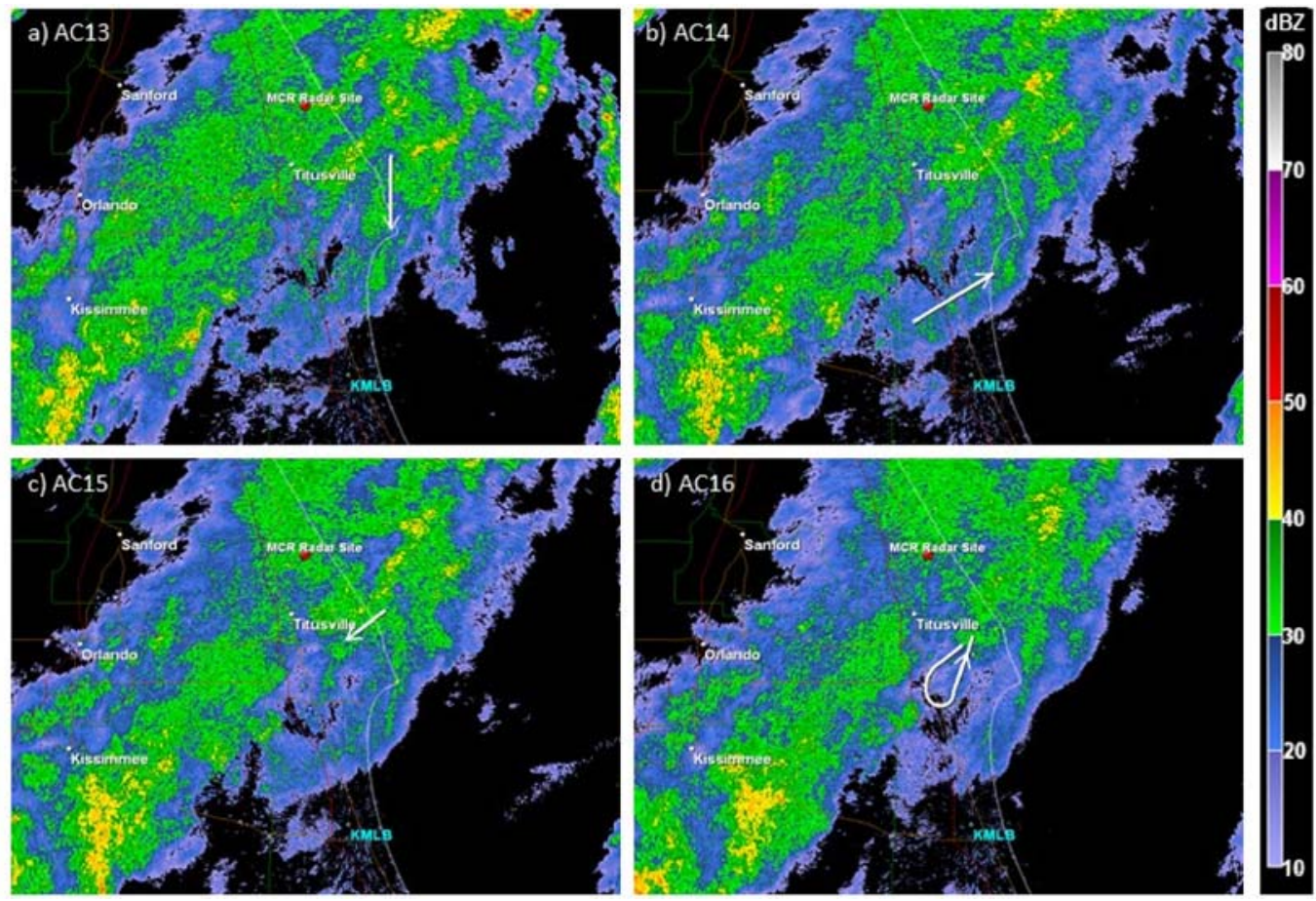

Figure 8. Base reflectivity on 01 August 2015 from the National Weather Service Melbourne radar (KMLB) and flight tracks (white line) during each MCR data file case is shown. The base 
reflectivity images shown are the closest available scans to the mean time of each flight segment. Arrows are included to depict the aircraft's direction of travel.
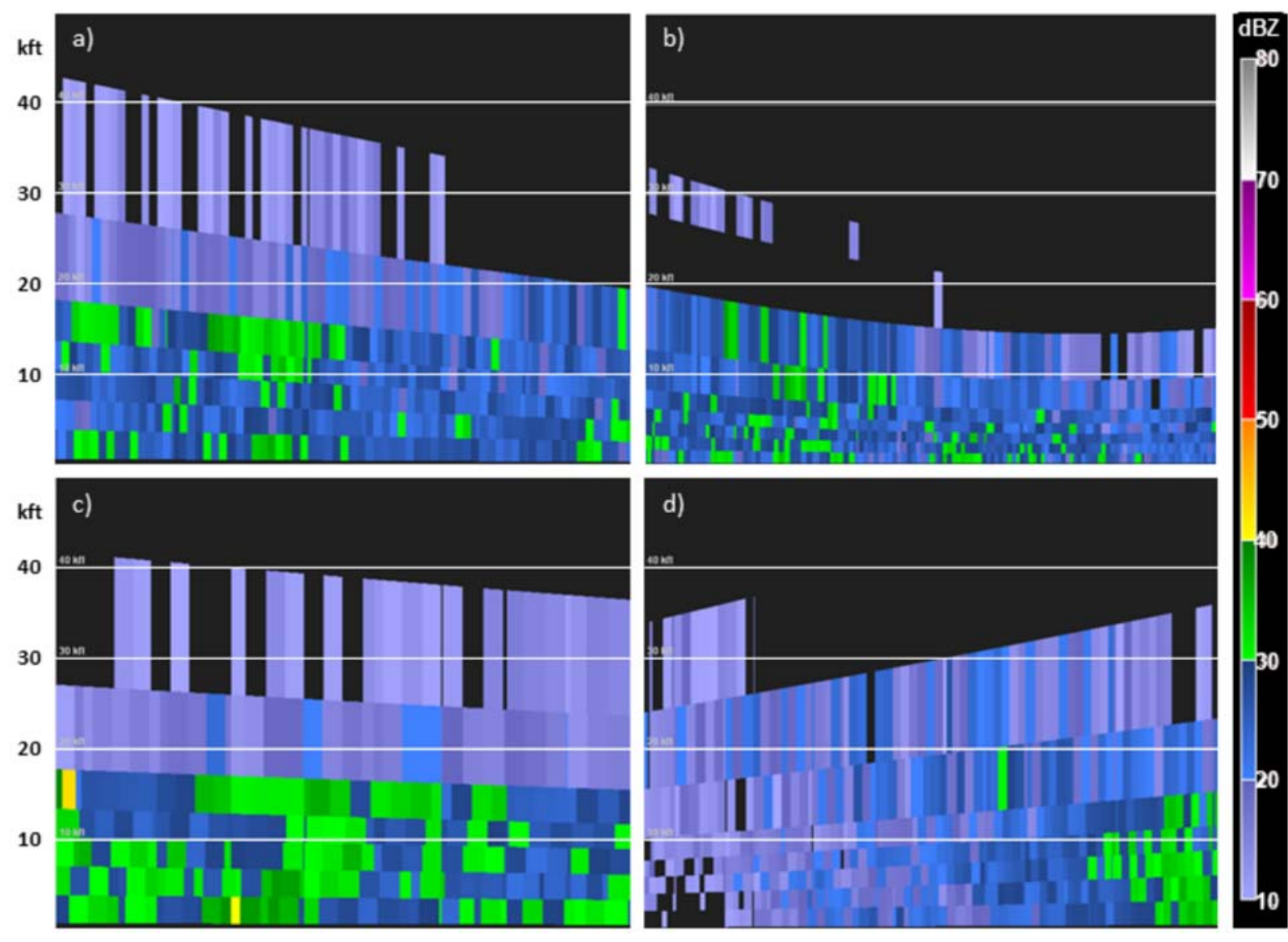

Figure 9. Cross-sections of the radar returns on 01 August 2015 from the National Weather Service Melbourne radar (KMLB) is shown for each case shown in Figure 8. Each cross-section is taken along the direction of travel of the aircraft except in (d) where it is taken along a line beginning at the apex of the aircraft's turn and ending at the approximate midpoint between the starting and ending points of the flight leg.

\section{MCR Reflectivity-Total Water Content Relationship}

The MCR tracking data on 01 August 2015 enables a comparison between observed MCR reflectivity and measured total water content (Figure 10) over a limited altitude range of $300 \mathrm{~m}$ $(11.3-11.6 \mathrm{~km})$ but over a wide range of median volume diameters and effective densities (Figure 4). The CAPE2015 mass (TWC)-reflectivity factor (Z) relationship using 1 second-averaged MCR reflectivity and corresponding 1 second-averaged Nevzorov TWC is given as TWC = $a Z^{b}$, where $a=0.0995 \pm 0.005$ and $b=0.492 \pm 0.0408$. The range in coefficients represents 
a $95 \%$ confidence interval whereby the power law line of best fit (solid black line) lies within the upper and lower uncertainty bounds (dashed lines) in Figure 10. The confidence interval represents a range between $2.10 \%$ and $15.4 \%$ uncertainty from the mean values of the coefficients at $0.5(-3)$ and $10(10) \mathrm{mm}^{6} \mathrm{~m}^{-3}(\mathrm{dBZ})$, respectively. The $95 \%$ confidence interval also represents a $4.50 \%$ and $33.4 \%$ difference between values on the upper and lower bounds of the confidence interval at 0.5 and $10 \mathrm{~mm}^{6} \mathrm{~m}^{-3}$, respectively. The uncertainty in TWC is given by

$$
\Delta T W C=T W C \sqrt{\left(\frac{\Delta a}{a}\right)^{2}+\left(\frac{\Delta Z^{b}}{Z^{b}}\right)^{2}}
$$

where

$$
\Delta Z^{b}=b \frac{\Delta Z}{Z}+\Delta b \ln Z
$$

The $95 \%$ fractional confidence interval is therefore $9 \%$ and $15 \%$ of TWC at the two extreme reflectivity limits of the fit, namely, -3 and $10 \mathrm{dBZ}$, respectively, assuming the imprecision of the reflectivity is $\Delta Z=1 \mathrm{dBZ}$. Bias errors in $\mathrm{Z}$ due to the sources mentioned in the next section would of course increase the fractional uncertainty in TWC further by

$$
\Delta T W C / T W C=b \Delta Z / Z \text {. }
$$

The CAPE2015 mass-reflectivity factor relationship from the four 01 August 2015 cases (AC13-AC16) lies in between the relationships from previous studies with the Heymsfield et al. (2005) (H2005) and Sayres et al. (2008) (S2008) relationships being the closest in TWC values and exponential slope. Both studies incorporated data from the CRYSTAL-FACE project which sampled similar data as is within this study. The variability of the $1 \mathrm{~Hz}$ comparison is due in part to differences in the particle habit that result in a non-unique radar return for a given total water content. 


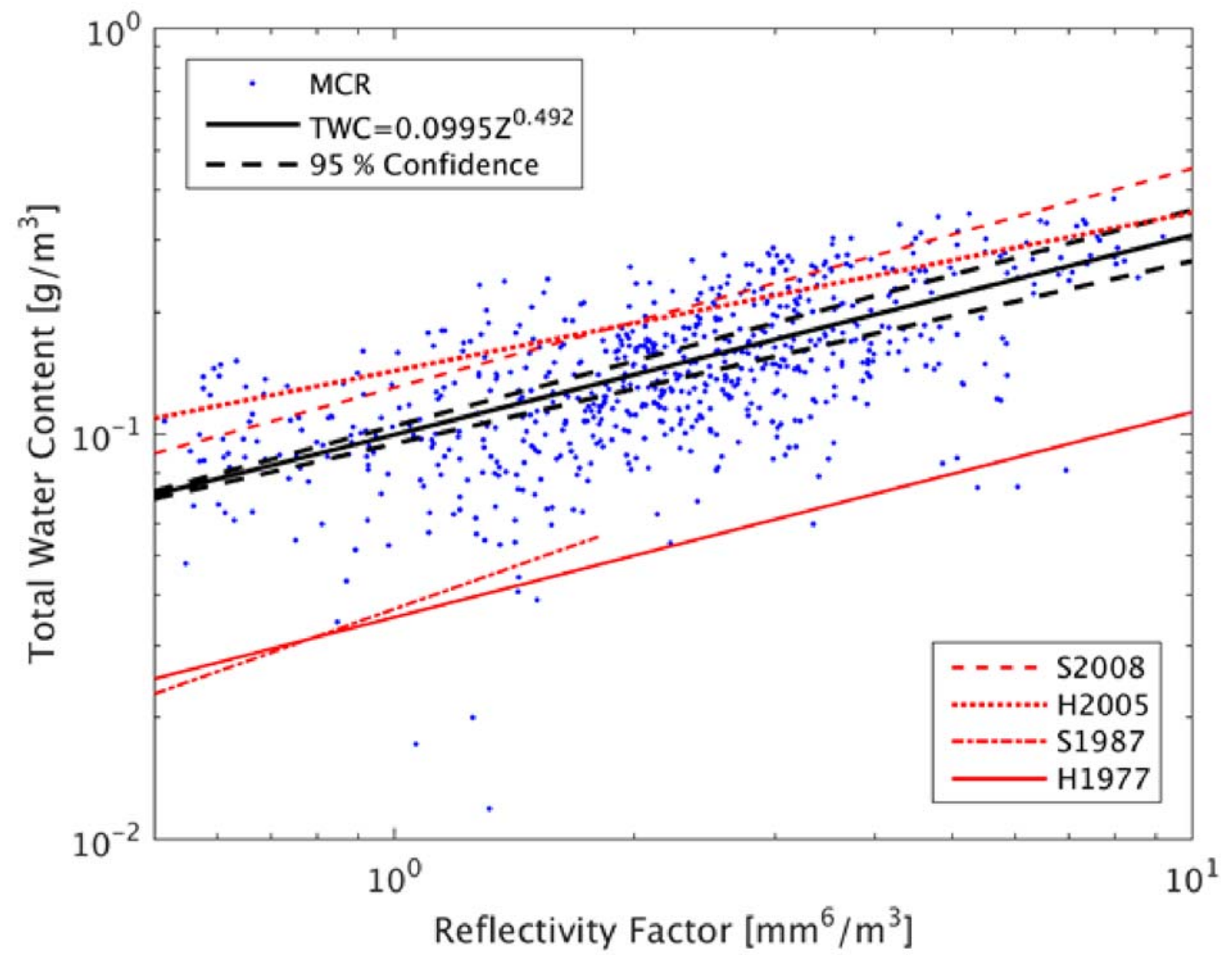

Figure 10. Plot showing the 1 second-averaged MCR reflectivity and corresponding 1 secondaveraged Nevzorov total water content (TWC, blue dots) for the aircraft tracking cases AC13AC16 on 01 August 2015. The solid black line represents the power law line of best fit to the data with the equation in the legend where TWC is the total water content $\left(\mathrm{g} \mathrm{m}^{-3}\right)$ and $\mathrm{Z}$ is the reflectivity factor $\left(\mathrm{mm}^{6} \mathrm{~m}^{-3}\right)$. The upper and lower bounds of the $95 \%$ confidence interval in the fit are shown in the dashed black lines. The red lines represent the radar reflectivity-ice water content relationships reported in previous studies: Heymsfield (1977) (H1997, solid line), Sassen (1987) (S1987, dash-dot line), Heymsfield et al. (2005) (H2005, dotted line), and Sayres et al. (2008) (S2008, dashed line).

\section{Comparisons of Radar Reflectivity Factor}

The radar reflectivity factors based on $1 \mathrm{~Hz}$ aircraft measurements on 01 August 2015 agree with the 1 second-averaged MCR measurements within aircraft measurement uncertainty for approximately $95 \%, 90 \%, 97 \%$, and $98 \%$ of the time for cases $\mathrm{AC} 13, \mathrm{AC} 14, \mathrm{AC} 15$, and AC16, respectively (Figure 11). Relative uncertainties in derived reflectivity are as high as \pm 455 
$\%$ and are on average $\pm 211 \%, \pm 226 \%, \pm 248 \%$, and $\pm 274 \%$ for cases AC13, AC14, AC15, and AC16, respectively. The high derived reflectivity relative uncertainties stem from the inclusion of large diameter particles that have few counts within the bin for the $1 \mathrm{~Hz}$ measurements. Since relative uncertainty is added across the merged size distribution, single-digit particle counts in large size bins significantly increase the totals of $Z_{e}$ and its relative uncertainty, thus low counts in large size bins contribute to most of the uncertainty in $Z_{e}$. A bias error range of $\pm 3 \mathrm{dBZ}$ is assumed for the MCR reflectivity which accounts for errors from the correction of attenuation during data post-processing, calibration errors, ground clutter contamination, specular returns from the aircraft, and range side lobes. Overall, the MCR reflectivity is lower than the derived reflectivity; however, both data sets have similar changes in reflectivity, especially throughout cases $\mathrm{AC} 14$ and $\mathrm{AC} 16$. Up to a 1 second offset may exist between the two data sets due to the averaging of the $160 \mathrm{~Hz}$ MCR data and aligning it with the $1 \mathrm{~Hz}$ aircraft measurements. 
a)

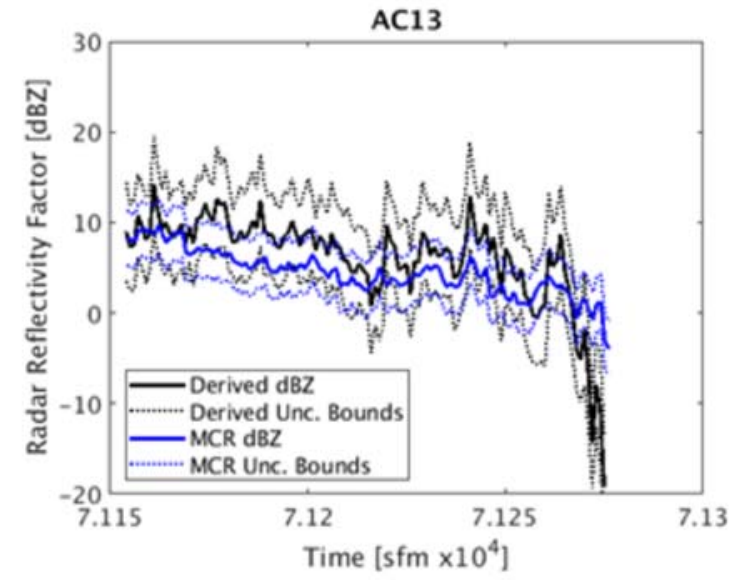

c)

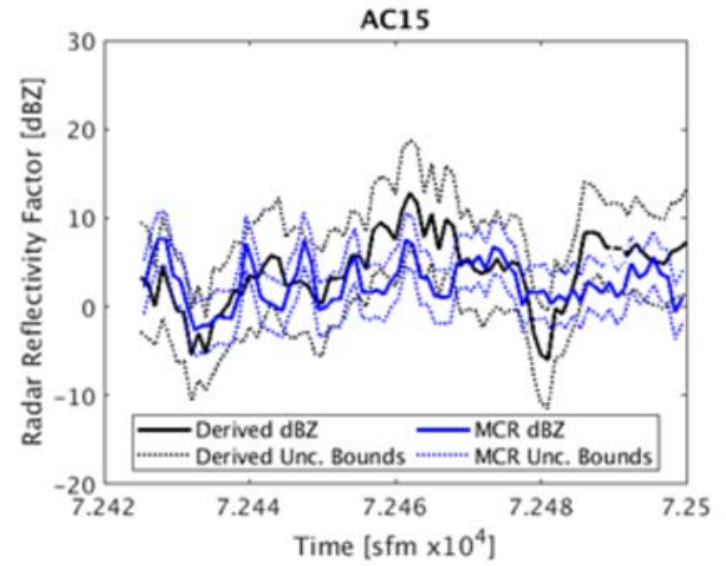

b)

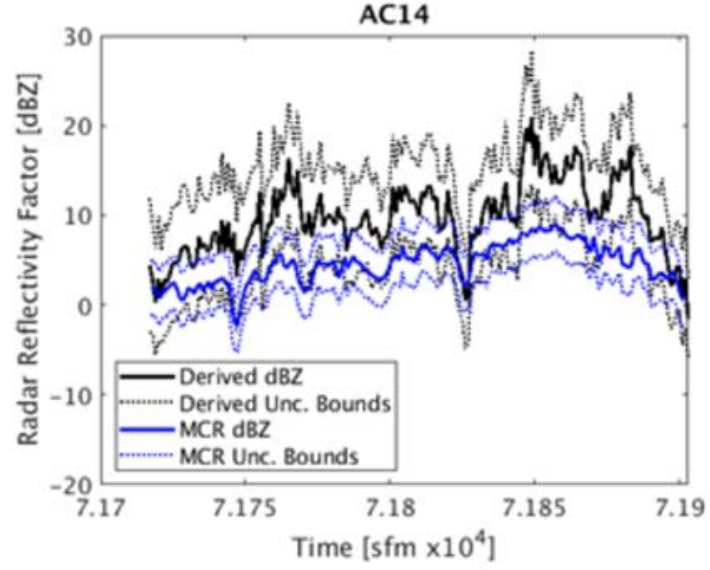

d)

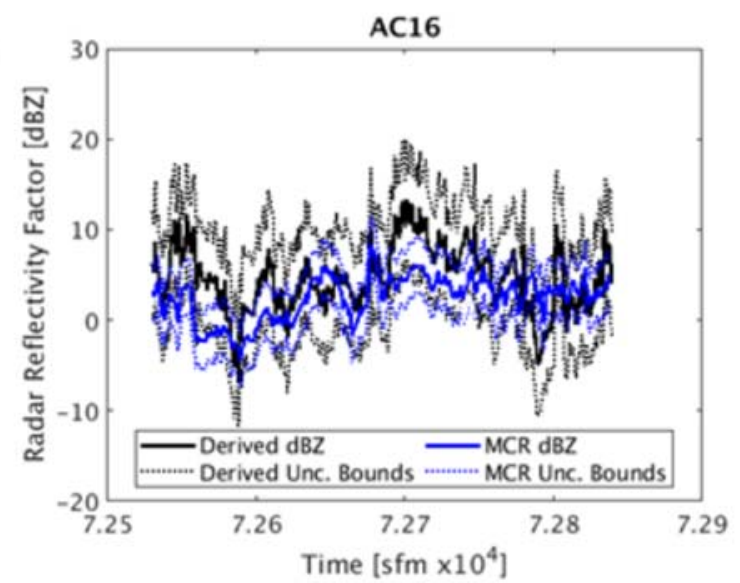

Figure 11. Comparisons between the MCR-observed reflectivity (blue lines) and aircraft-derived reflectivity (black lines) at $1 \mathrm{~Hz}$ for all four aircraft tracking scanning strategy cases are shown. The MCR-observed wideband reflectivity shown is an average of $10 \mathrm{~m}$ in range surrounding the aircraft ( $\pm 5 \mathrm{~m}$ in range from range of aircraft). The upper and lower uncertainty (unc.) bounds are plotted with dotted lines for both the MCR-observed reflectivity (dotted blue lines) and derived reflectivity (dotted black lines). $\mathrm{A} \pm 3 \mathrm{dBZ}$ uncertainty in the MCR-observed reflectivity is assumed. The uncertainty bounds for the derived reflectivity are derived from $\delta z$ in Equation 6.

To illustrate the offset between the aircraft derived and MCR reflectivity, $10 \mathrm{~s}$ average data is compared (Figure 12). The 1 second-averaged data (Figure 11) have uncertainties greater than $\pm 200 \%$ on average, whereas averaging every 10 seconds lessens the uncertainties to $\pm 72 \%, \pm 92$ $\%, \pm 96 \%$, and $\pm 94 \%$ for cases $\mathrm{AC} 13, \mathrm{AC} 14, \mathrm{AC} 15$, and $\mathrm{AC} 16$, respectively (Figure 12). The peak uncertainty for all four cases shrinks to $\pm 150 \%$. The agreement between the two data sets 
also shrinks to $85 \%, 26 \%, 75 \%$, and $77 \%$ of the time for cases $\mathrm{AC} 13, \mathrm{AC} 14, \mathrm{AC} 15$, and AC16, respectively, with the derived reflectivity higher than the MCR reflectivity by 2-10 dBZ.

a)

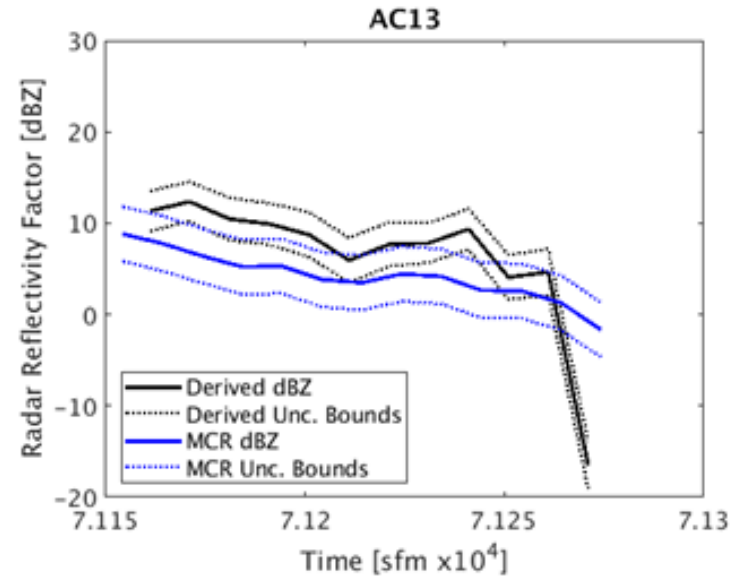

c)

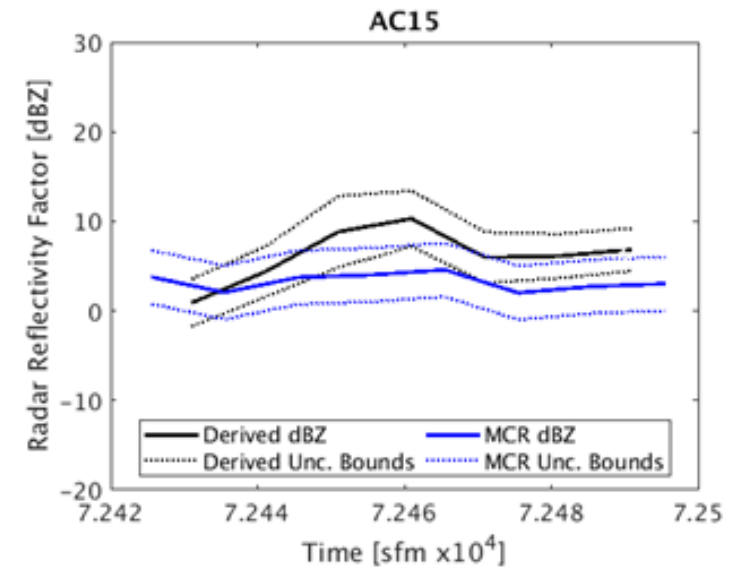

b)

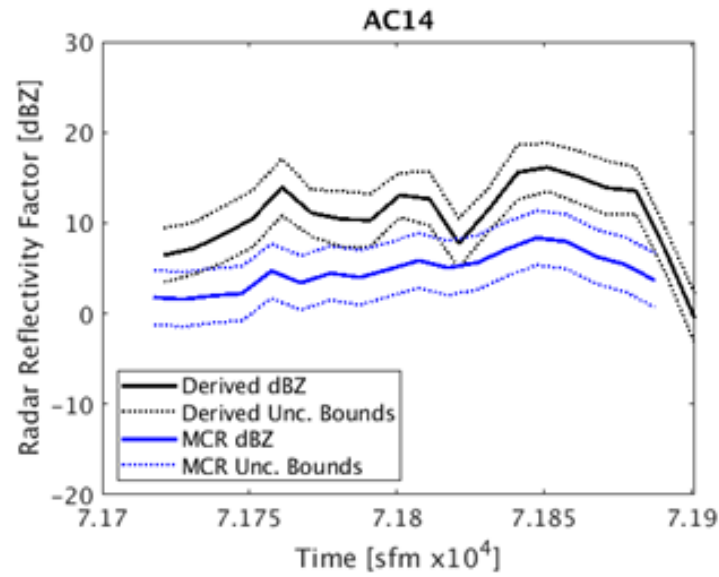

d)

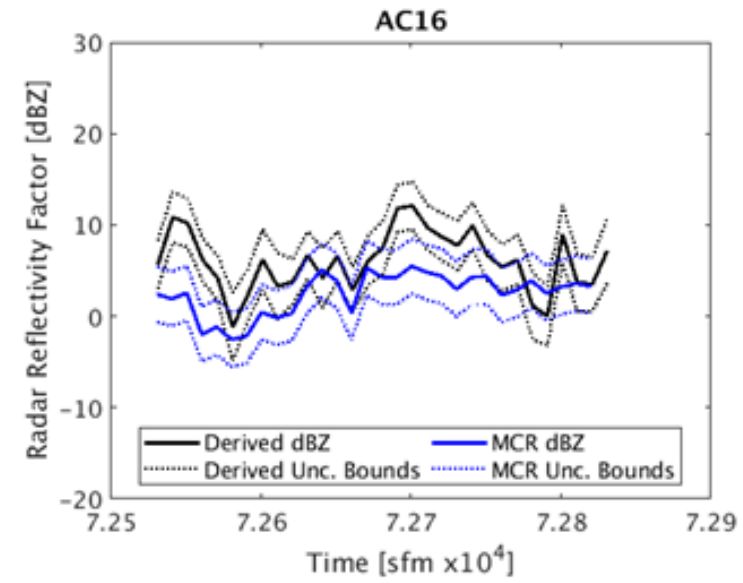

Figure 12. MCR-observed and aircraft-derived reflectivity is shown as in Figure 11 but for an average of 10 seconds.

The lessened uncertainties for a longer averaging time are due in part to there being more particles within each particle size spectrum and therefore each size bin, which lessens the uncertainties in particle counts per Poisson Counting Statistics (Equation 5). It would seem that averaging for even longer time periods would continue the trend of lessening the uncertainties in $Z_{e}$, but the assumption that the uncertainties in effective liquid particle size are negligible would become invalid at some averaging length. More particles counted within an average particle size 
distribution may mean lower particle concentration uncertainty, but it may also mean higher uncertainty in average particle diameter due higher chances of a greater range of particle sizes being measured. The averaging length at which the negligible effective liquid particle diameter uncertainty becomes invalid is beyond the scope of this study. Future work will look at an optimization of the equations involved in deriving $Z_{e}$ that takes into account uncertainty in channel bin diameter and uses the best bin widths to give the lowest overall uncertainty in $Z_{e}$.

Since all four aircraft tracking cases have similar meteorological conditions and similar particle size distributions (Figure 13), details of the observations from cases AC13 and AC14 are investigated to discern reasons for the differences in the aircraft/radar comparison. Figure 14 and Figure 15 show the important parameters related to the derived reflectivity values for the non-agreement case of AC14. Measurements during the AC14 tracking case are taken at a constant altitude and temperature of approximately $11.3 \mathrm{~km}$ and $-43{ }^{\circ} \mathrm{C}$, respectively (Figure 14a). Figure $14 \mathrm{c}$ shows $2 \mathrm{D}-\mathrm{S}$ particle images indicating particles are relatively large ice crystal aggregates upwards of $500 \mu \mathrm{m}$. The one second-average aspect ratio for AC14 is 0.72 with little variation as values at the image locations $(1,2$, and 3$)$ are $0.69,0.72$, and 0.75 , respectively. Because of the proximity of the aspect ratios to 1.0 , the underlying spherical particle assumption is assumed to be valid for this case. The particle size distributions from the 2D-S and HVPS3 show a nearly seamless transition between the different probe-measured particle size distributions (Figure 14b). Additionally, it indicates that the 1,000 $\mu \mathrm{m}$ cutoff between the 2D-S and HVPS3 particle size distributions is sufficient in the creation of the merged spectrum in Figure 13. Figure $14 \mathrm{~d}$ shows the necessity of merging the 2D-S and HVPS3 data at $1,000 \mu \mathrm{m}$ since the peak in the derived reflectivity size spectrum (approximately $2.5 \mathrm{~mm}$ ) is outside of the 2D-S observing size range. Particles larger than the 2D-S maximum observing size are present 
in the data of which significantly contribute to $Z_{e}$; however, overall maximum particle size is well below $1.92 \mathrm{~cm}$ so effects from HVPS3 particle reconstruction are minimal.

Figure 15 breaks down Equation 4 into the measurements that make up the derived reflectivity for the AC14 non-agreement case. Figure 15a shows the comparisons of the MCR and derived reflectivity data with box-and-whisker plots. Although the medians of each data set are only approximately $5 \mathrm{dBZ}$ apart, the interquartile ranges of each data set do not overlap, indicating the disagreement in the two data sets in that the derived reflectivity is both higher and more variable than the MCR reflectivity. Figure $15 \mathrm{~b}$ shows the summation of particle concentrations ( $N$ in Equation 4 ) and counts using 2D-S size bins greater than $105 \mu \mathrm{m}$. The low particle concentrations and counts are the main source of high uncertainty in the one secondaveraged $Z_{e}$. Figure $15 \mathrm{~d}$ shows the sum of the sixth moment of the liquid-equivalent diameters ( $d$ in Equation 4) greater than $105 \mu \mathrm{m}$ in diameter. Note the similarity in the order of magnitude between the sums of the sixth moment of liquid-equivalent diameters and the particle concentrations, suggesting that the particle concentrations hold as equal weight as the diameters in the derivation of $Z_{e}$. The similarity in orders of magnitude helps to negate the effects of low particle counts in any size bins used in the derivations. Figure $15 \mathrm{c}$ indicates the derived particle densities (Equation 2) during AC14 are small (generally less than $100 \mathrm{~kg} \mathrm{~m}^{-3}$ ) due to high concentrations of large particles. 


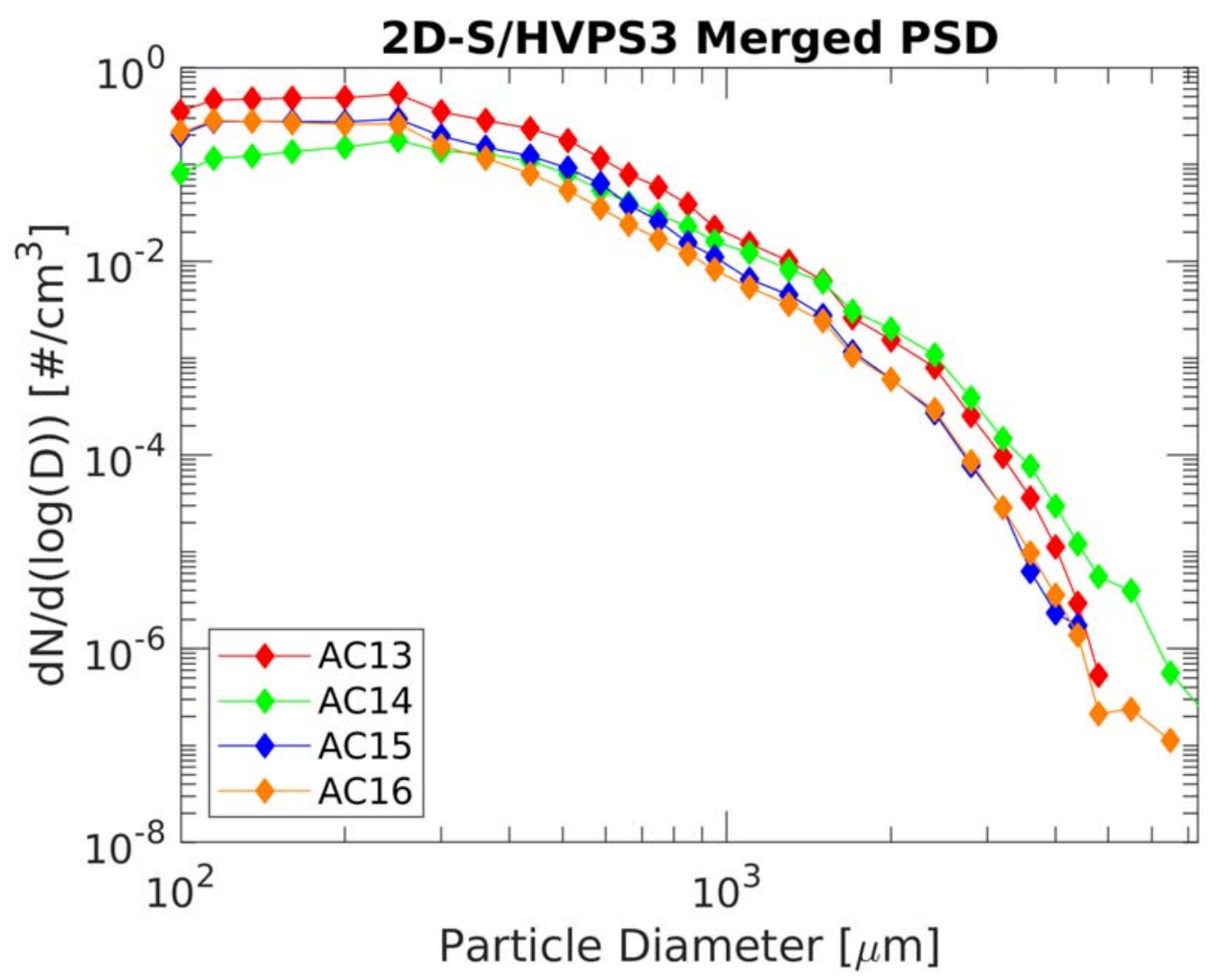

Figure 13. The particle size distributions (PSDs) for aircraft tracking cases AC13-AC16 are shown. The 2D-S particle concentrations are shown below 1,000 $\mu \mathrm{m}$ and the HVPS3 particle concentrations are shown from $1,000 \mu \mathrm{m}$ and above ("merged PSD"). Each PSD represents the average particle concentrations during the entirety of each tracking case in seconds from midnight (sfm): AC13 is from 71154.2-71277.7 sfm, AC14 is from 71717.4-71903.3 sfm, AC15 is from 72425.5-72500.0 sfm, and AC16 is from 72530.0-72839.1 sfm. The particle concentrations are normalized by the log of the size of each size bin created during SODA2 processing, and the diamonds represent the midpoints of those size bins. 
a)

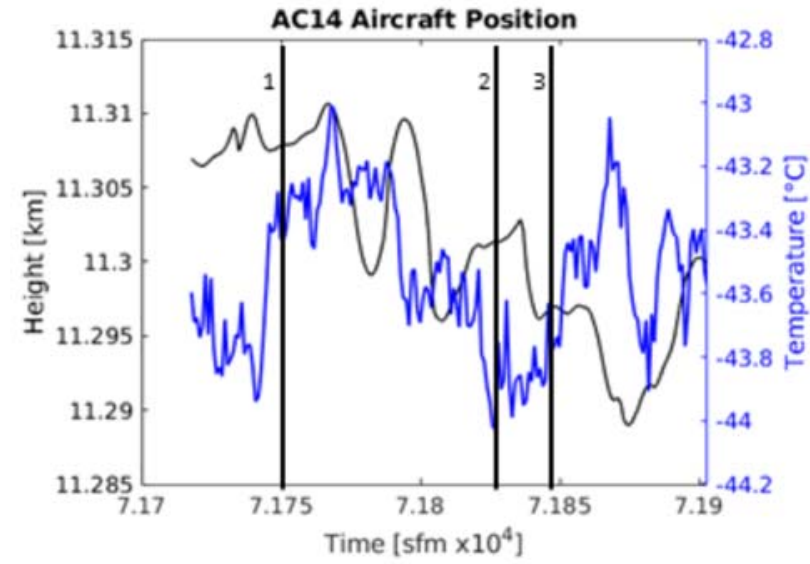

c)

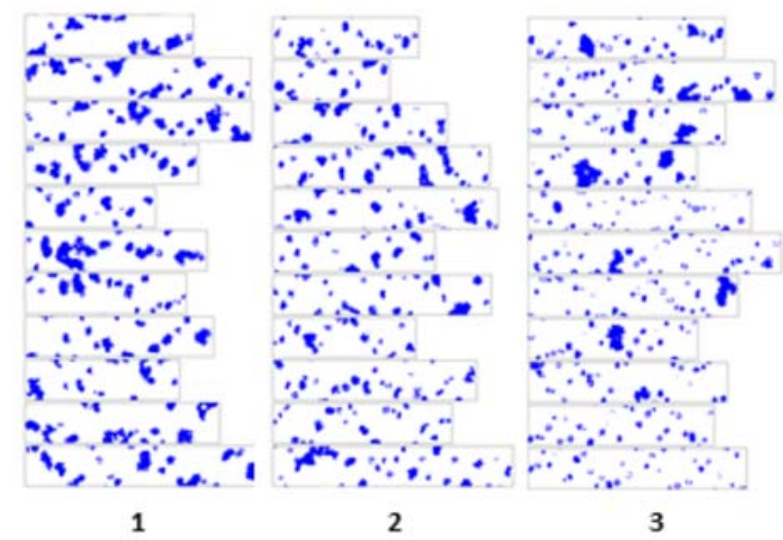

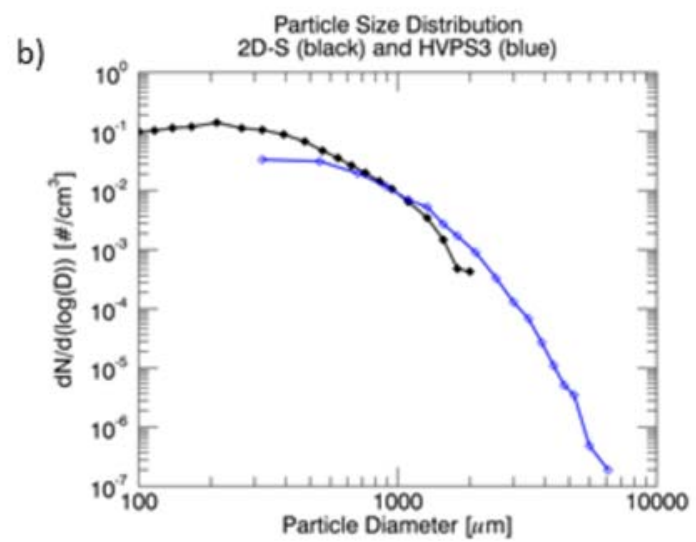

d)

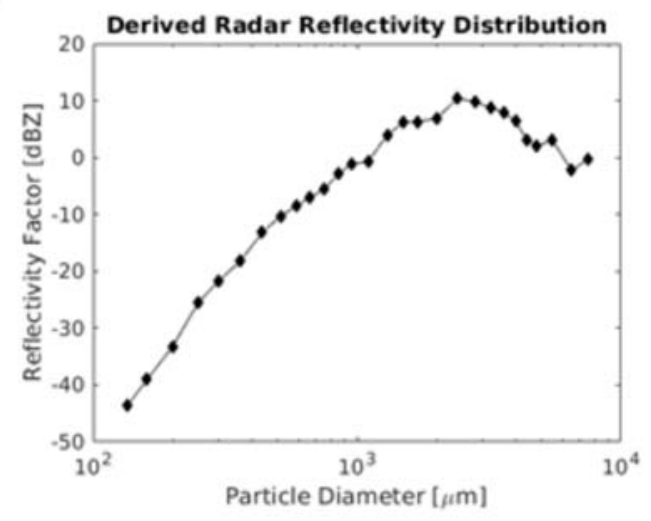

Figure 14. Data collected from the Citation Research Aircraft during the AC14 tracking case on 01 August 2015 is shown. Plot (a) shows the GPS altitude of the aircraft (black line) and corresponding ambient air temperature (blue line) per time in seconds from midnight (sfm). The vertical lines labeled 1-3 correspond to particle images in plot (c) from the Two-Dimensional Stereographic (2D-S) probe. Plot (b) shows the mean log-normalized particle size distribution of the observed particles from the 2D-S (black line) and HVPS-3 (blue line) for particles greater than 105 um over the entirety of the AC14 case. The diamonds represent the midpoint of each 2D-S size bin created during data post-processing. Plot (c) shows 2D-S particle images from various times during case AC14. Image (1) is at $71750 \mathrm{sfm}$, image (2) is at $71826 \mathrm{sfm}$, and image (3) is at $71849 \mathrm{sfm}$. The horizontal axis of each rectangle containing particle images is time and the vertical axis is along the array of photodiodes (128 dots representing $1280 \mu \mathrm{m}$ in total size). Measurements by the 2D-S are taken asynchronously so the horizontal axes of each rectangle containing the images represent different lengths of time, but each segment 1-3 represents approximately $0.5 \mathrm{~s}$ of particle data. Plot (d) shows the mean distribution of derived reflectivity from the probe data over the entirety of the AC14 case. The diamonds represent the midpoints of each size bin created during data post-processing. 

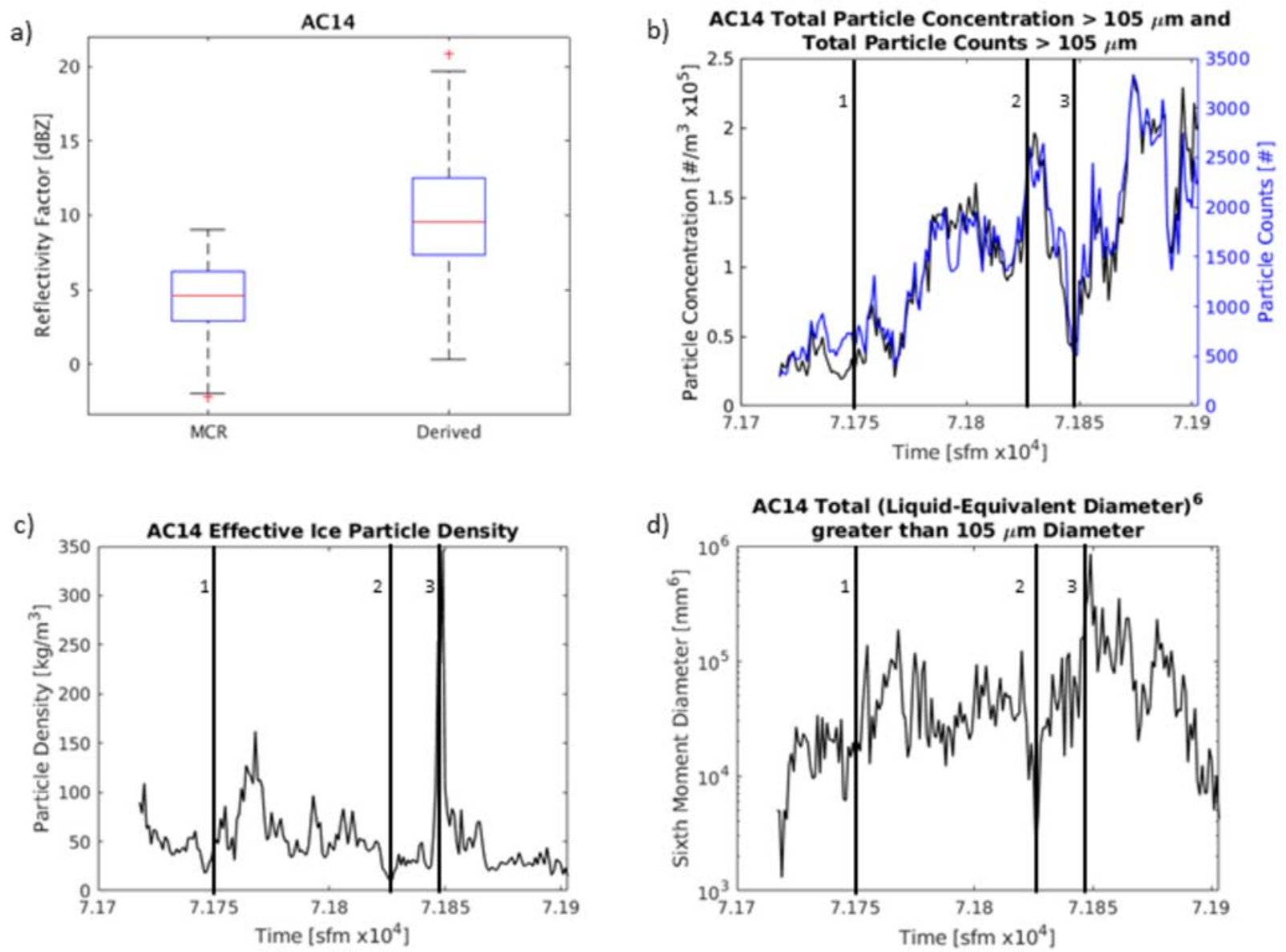

Figure 15. Data pertaining to the calculation of the derived reflectivity during the AC14 case is shown. Plot (a) shows box-and-whisker plots of 1 second-averaged MCR-observed (left) and aircraft-derived (right) reflectivity data for case AC14. The middle red line is the median of the data; the bottom and top of each box is $25^{\text {th }}$ and $75^{\text {th }}$ percentiles, respectively; the whiskers extend to the furthest data points not considered outliers; and the red pluses are outliers within the data sets. The MCR reflectivity is an average of $10 \mathrm{~m}$ in range surrounding the aircraft $( \pm 5 \mathrm{~m}$ in range from range of aircraft). Plot (b) shows the total particle concentration and total number of particles greater than $105 \mu \mathrm{m}$ (black and blue lines, respectively). Plot (c) shows the derived effective ice particle density (Equation 2). Plot (d) shows the sixth moment of the summation of the liquid-equivalent diameter of particles greater than $105 \mu \mathrm{m}$ (Equation 1). The numbered vertical lines in (b-d) correspond to the times of the Two-Dimensional Stereographic (2D-S) probe particle images in Figure 14c.

Figure 16 and Figure 17 outline the details of the observations of tracking case AC13. Cases $\mathrm{AC} 13$ and $\mathrm{AC} 14$ are the most similar in length of time out of the four tracking cases, but in contrast with case $\mathrm{AC} 14$, the derived reflectivity during case $\mathrm{AC} 13$ generally agrees with the MCR reflectivity (Figure 11a, Figure 12a, and Figure 17a). The aircraft altitude and ambient 
temperature during case $\mathrm{AC} 13$ are comparable to that of case AC14 at approximately $11.3 \mathrm{~km}$ and $-43.4{ }^{\circ} \mathrm{C}$, respectively (Figure 16a). The particle habits and sizes during case AC13 are similar to case AC14 (Figure 16c). The differences between the two cases are in the size distributions (Figure 16b and Figure 16d), particle concentrations and counts greater than 105 $\mu \mathrm{m}$ (Figure 17b), effective particle densities (Figure 17c), and the sixth moment of effective liquid particle sizes (Figure 17d). Although the smaller bins have a higher particle concentration than case AC14, the larger bins (which contribute much more to the summation of radar reflectivity factor) have less particle concentration. The peak of the reflectivity factor distribution is equivalent to $\mathrm{AC} 14$ at approximately $2.5 \mathrm{~mm}$ but is lower at approximately $8 \mathrm{dBZ}$ rather than approximately $12 \mathrm{dBZ}$ for case $\mathrm{AC} 14$. The largest observed particle diameters are also lower and contribute less to the reflectivity factor distribution by dropping off and ending sooner than during case AC14. Effective particle densities are lower on average for case AC13 (Figure 17c) than case AC14 (approximately 53 and $37 \mathrm{~km} \mathrm{~m}^{-3}$ for cases $\mathrm{AC} 14$ and $\mathrm{AC} 13$, respectively) and the effective densities are not above $80 \mathrm{~kg} \mathrm{~m}^{-3}$. The total particle concentrations and counts are higher than case AC14, but the higher concentrations of smaller particles observed by the 2D-S (Figure 16b) contribute to the concentration and counts totals much more than to the summation of radar reflectivity factor. The higher concentration of smaller particles also contributes to the sixth moment of effective liquid particle sizes being an order of magnitude higher than AC14. 
a)

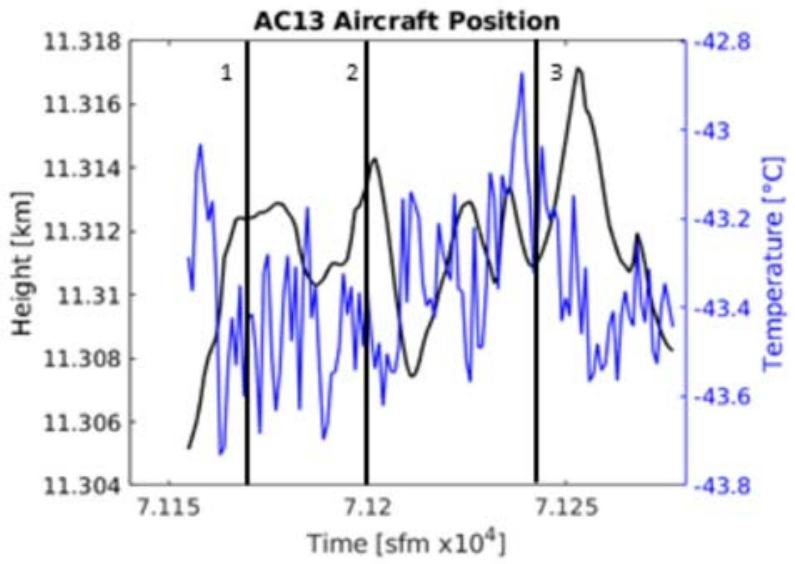

c)

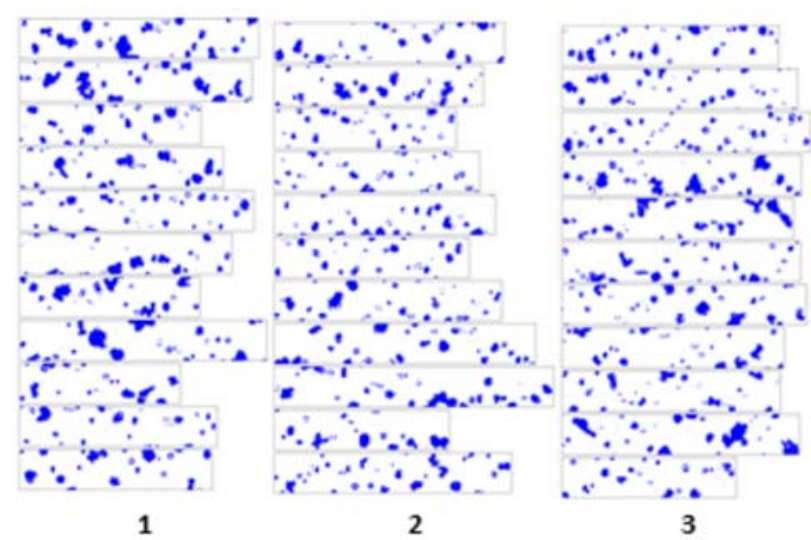

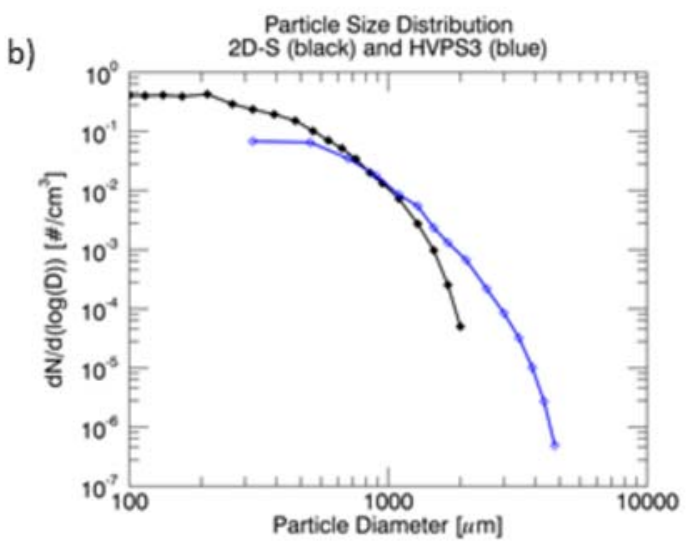

d)

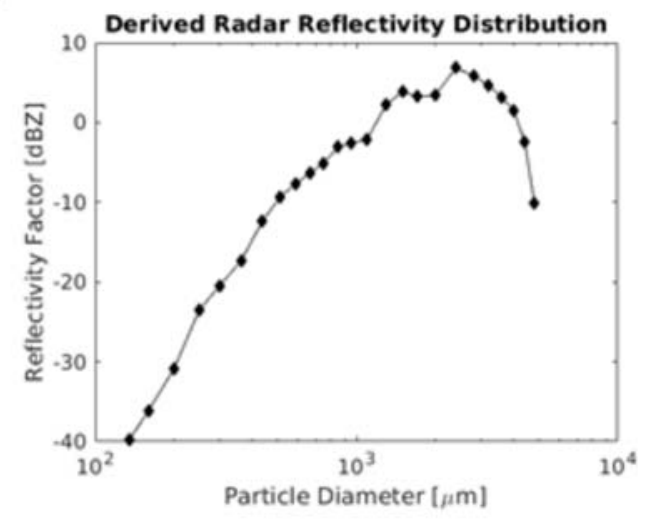

Figure 16. Data collected from the Citation Research Aircraft is shown as in Figure 14 but for case AC13 on 01 August 2015. The vertical lines (1-3) in plot (a) correspond with the samples of Two-Dimensional Stereographic probe (2D-S) particle images in plot (c). The times are in Universal Coordinated Time (UTC) seconds from midnight on the day of the flight (sfm): image (1) at $71167 \mathrm{sfm}$, image (2) at 71200, and image (3) at $71240 \mathrm{sfm}$. 

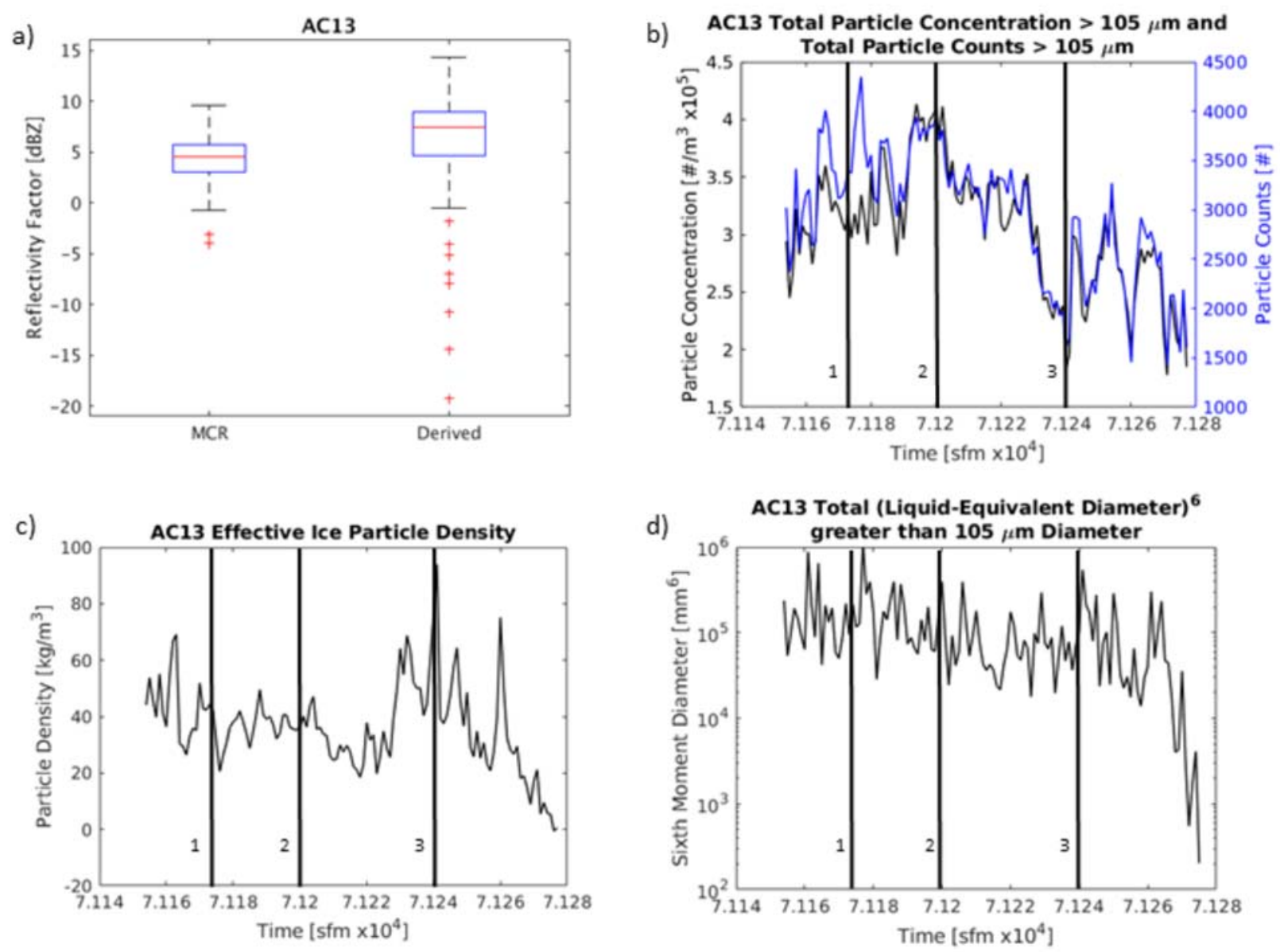

Figure 17. Data pertaining to the calculation of the derived reflectivity is shown as in Figure 15 but for case AC13 case on 01 August 2015. The numbered vertical lines in (b-d) correspond to the times of the Two-Dimensional Stereographic probe (2D-S) particle images in Figure 16c.

The differences between tracking cases $\mathrm{AC} 13$ and $\mathrm{AC} 14$ highlight that multiple factors could be causing the differences in agreement between the derived and observed reflectivity for cases $\mathrm{AC} 13$ and $\mathrm{AC} 14$ and in general for all the tracking data. Although the particle size distributions of the 2D-S and HVPS3 overlap at 1,000 $\mu \mathrm{m}$ in both the bin sizes and subsequent particle concentrations, a perfect fit is not achieved between the distributions. A consistent "bump" in the merged distributions exist in the next few size bins greater than $1,000 \mu \mathrm{m}$ for all tracking cases (Figure 13), suggesting that the HVPS3 is oversampling particles compared to the 2D-S in the size range between 1.0 to $1.6 \mathrm{~mm}$. Case AC14 shows the largest "bump" in the size 
distributions in the 1.0 to $1.6 \mathrm{~mm}$ size range, and since the particle diameters larger than $1 \mathrm{~mm}$ contribute the most to the summation of radar reflectivity factor (Figure 15a), the "bump" could contribute to the disagreement between the derived and MCR reflectivity data sets. A smoothing or blending of the particle size distributions may alleviate the disagreements between the derived and MCR reflectivity data sets, especially with case AC14. A second possible contribution to the disagreement between the MCR and derived reflectivity data sets is the assumption of spherical particles inherent to the derivation of $Z_{e}$. The area ratio of either each particle or a time step average could be incorporated into the effective density derivations to adjust how the total mass is distributed. The method of determining the maximum dimension of the particles may also need to change, and both adjustments are beyond the scope of this study. A third possible contribution to the disagreement during tracking case $\mathrm{AC} 14$ could be the attenuation of the $\mathrm{MCR}$ wideband beam by the precipitation below the anvil. The distance between the MCR and the aircraft is the largest during case $\mathrm{AC} 14$ and the entirety of that distance is filled with precipitation (Figure $8 b$ and Figure 9b); therefore, the effects of beam attenuation could be largest during case AC14. However, estimates of the two-way attenuation (Doviak and Zrnić 1984) based on the available narrowband data for each of the tracking cases show it to be no more than approximately $0.1 \mathrm{dBZ}$. Therefore, the attenuation of the beam alone can neither explain the disagreement between cases $\mathrm{AC} 13$ and $\mathrm{AC} 14$ nor the large differences between the derived and MCR reflectivity data sets. The final possible contribution to the data disagreement could be an unknown offset between the MCR and derived reflectivity data sets suggested by the agreement in the trends of the values but not the values themselves. Unexpected or unusual contamination from the tracking of the aircraft could cause such an offset, and the cause and quantification of the contamination seen is still under investigation. 


\section{SUMMARY AND CONCLUSIONS}

A summer 2015 field project was conducted near Cape Canaveral, Florida, and was designed to help the United States Navy continue improvements to both the relationship between radar reflectivity and water content for the MCR and the representation of ice within the Navy's computer forecast models. During the field project, in-situ and remote measurements of thunderstorm anvils near Cape Canaveral, Florida, were concurrently obtained. The North Dakota Citation Research Aircraft obtains measurements using airborne cloud probes, and the MCR obtains measurements using both its narrowband and wideband beams with along-range resolutions of $37 \mathrm{~m}$ and $0.5 \mathrm{~m}$, respectively. The aircraft location is downlinked to the MCR in real-time which enables a specialized scan to be performed that tracks the aircraft within the MCR's wideband beam. The specialized tracking scan thus allows for concurrency between the in-situ and radar measurements for prolonged periods of flight, a first in meteorology.

Equivalent radar reflectivity factor (referred to as the derived reflectivity) is derived using effective liquid particle sizes and total particle concentrations from the 2D-S and accounts for the dielectric factor differences between water and ice. Effective liquid particle sizes are derived from the 2D-S two-dimensional particle size measurements and an effective density of the ice particles assuming the mass of water is equal to the mass of ice. The effective ice particle density is derived using the total particle mass from all measured particles obtained using a Nevzorov Water Content Probe, along with the total particle volume obtained from a merged particle size spectrum from the 2D-S and HVPS3. The effective particle density $\left(\rho_{e}\right)$ accounts for the presence of non-solid ice particles and is found to be $\rho_{e}=(0.00346 \pm 0.00108) D_{V}{ }^{(-1.03 \pm 0.0820)}$, where $D_{V}$ is the median volume diameter, within 
a $95 \%$ confidence interval of the power law line of best fit. The $\rho_{e}$-diameter relationship is good for particles whose median volume diameter is $100 \mu \mathrm{m}$ to $3 \mathrm{~mm}$ and for ambient temperatures of -30 to $-50{ }^{\circ} \mathrm{C}$. A relationship between the observed reflectivity factor from the MCR ( $Z$ ) and measured TWC from the Nevzorov is found to be $T W C=(0.0995 \pm$ $0.005) Z^{(0.492 \pm 0.0408)}$. The Z-TWC relationship is valid for thunderstorm cirrus anvils with ambient temperatures less than $-40{ }^{\circ} \mathrm{C}$ and observed reflectivity factor in the range from -3 to 10 dBZ. Previous published $\rho_{e}$-diameter and $Z_{e}$-water content relationships are in general agreement with the CAPE2015 results.

The derived reflectivity is compared to the reflectivity factor from the wideband beam of the MCR. An average of $95 \%$ of examined one second-averaged values of derived reflectivity and observed wideband reflectivity factor agree within their respective uncertainties across a -20 to $20 \mathrm{dBZ}$ range. The uncertainty in the derived reflectivity data is mostly attributed to uncertainties in the particle counts per size bin, and errors up to $\pm 455 \%$ are present in the data. 10 second-averaged data is also examined and the agreement between the MCR and derived reflectivity data shrinks to $71 \%$ on average. The worsening correlation with increased averaging length shows that the two radar reflectivity factor data sets do not compare unless uncertainties are large; however, one tracking case $(\mathrm{AC} 14)$ has a higher disagreement than the rest. The disagreement between the MCR and derived reflectivity data sets is mostly attributed to the method of merging the 2D-S and HVPS3 particle size distributions.

The CAPE2015 field project improves upon previous studies by using concurrent measurements between in-situ and remote platforms to create a data set that is co-located both spatially and temporally. Due to the ability to track the Citation Research Aircraft by the MCR in real-time, the two platforms are able to sample the same part of the cloud at the same time 
regardless of aircraft altitude, speed, or direction of flight. A small offset of up to $500 \mathrm{~m}$ between the MCR's wideband beam and the Citation Research Aircraft exist in order to mitigate contamination of the return signal by the aircraft. Rather than the uncertainties in comparisons between in-situ and remote data resulting from spatial or temporal differences between the data as in previous studies [e.g. Sayres et al. (2008)], the uncertainties in the comparisons of CAPE2015 field project data are determined to result from those inherent to the in-situ particle measurements. The high sensitivity of the MCR allows for the estimation of cloud water content from observed reflectivity factor within an uncertainty of $\pm 17 \%$. More data, especially aircraft tracking data that covers more altitudes and meteorological conditions, is needed in future studies. Future work also includes finding the true uncertainties in $Z_{e}$ by optimizing the equations involved in deriving $Z_{e}$ and/or the widths of the size bins created during data postprocessing. 


\section{APPENDIX A}

The processing of the aircraft data from the CAPE2015 field project is completely automated after one script, process_all_utc, is executed. The process_all_utc script was written for the specific configuration of the aircraft during the CAPE2015 field project (Figure 1) and can process data from multiple field projects. It first calls the ADPAA processing which converts the binary file from the data acquisition system to text files with a common file format and then calls the SODA2 processing for the 2D-S and HVPS3 via scripts that link SODA2 processing to ADPAA (linkage_soda). For data within this paper, the Level 3 ADPAA processing code nevzorov2twc.py converts Nevzorov voltages into water content values. The Level 4 twods_conc2bulk_ice.py code incorporates Equations 1-6 using 2D-S and Nevzorov data to calculate bulk optical array probe properties such as $Z_{e}$ and $\rho_{e}$. The create_merge_spectra module is used to create the merged size spectra between the 2D-S and HVPS3. Cplot2 within ADPAA is used to visualize aircraft data time series and particle size distributions.

Matlab programs aircraft_dBZ_error_plots.m, $Z$ _WC.m, and beam_height.m plots the derived and observed reflectivity values (Figure 11 and Figure 12), calculates and plots the reflectivity factor-water content relationships (Figure 10), and calculates the MCR beam height (Figure 2), respectively. A workflow Matlab program thesis_plots.m creates most of the other plots seen in this paper. 


\begin{abstract}
APPENDIX B
The sensitivity of the MCR follows the version of the radar equation that yields values in dBZ. Using the sensitivity values given in Schmidt et al. (2019) and following the logarithmic (dBZ) version of the radar equation, the $50 \mathrm{~km} \mathrm{MCR} \mathrm{sensitivity}\left(S_{50}\right)$ in Table 1 is calculated by:

$$
S_{50}=S_{R}-20 \log R+20 \log r
$$

where $S_{R}(\mathrm{dBZ})$ is the sensitivity at range $R(\mathrm{~m})$ and $r$ is $50,000 \mathrm{~m}$ in range.
\end{abstract}




\section{REFERENCES}

Bansemer, A., 2016: System for OAP Data Analysis. GitHub, Inc.,.

Brandes, E. A., J. Vivekanandan, J. D. Tuttle, and C. J. Kessinger, 1995: A Study of Thunderstorm Microphysics with Multiparameter Radar and Aircraft Observations. Mon. Wea. $\quad$ Rev., $\quad$ 123, 3129-3143, https://doi.org/10.1175/15200493(1995)123<3129:ASOTMW>2.0.CO;2.

Bringi, V. N., V. Chandrasekar, and R. Xiao, 1998: Raindrop axis ratios and size distributions in Florida rainshafts: an assessment of multiparameter radar algorithms. IEEE Transactions on Geoscience and Remote Sensing, 36, 703-715, https://doi.org/10.1109/36.673663.

Brown, P. R. A., and P. N. Francis, 1995: Improved Measurements of the Ice Water Content in Cirrus Using a Total-Water Probe. J. Atmos. Oceanic Technol., 12, 410-414, https://doi.org/10.1175/1520-0426(1995)012<0410:IMOTIW>2.0.CO;2.

Cotton, R. J., and Coauthors, 2013: The effective density of small ice particles obtained from in situ aircraft observations of mid-latitude cirrus: Effective Density of Small Ice Particles. Quarterly Journal of the Royal Meteorological Society, 139, 1923-1934, https://doi.org/10.1002/qj.2058.

Delene, D. J., 2011: Airborne data processing and analysis software package. Earth Sci Inform, 4, 29-44, https://doi.org/10.1007/s12145-010-0061-4.

—, K. Hibert, M. Poellot, and N. Brackin, 2019a: The North Dakota Citation Research Aircraft Measurement Platform. 2019 SAE International Conference on Icing of Aircraft, Engines, and Structures,. 
—, A. Skow, J. O’Brien, N. Gapp, S. Wagner, and K. Hibert, 2019b: Airborne Data Processing and Analysis Software Package. Zenodo,.

Doviak, R. J., and D. S. Zrnić, 1984: Doppler radar and weather observations. Academic Press, $458 \mathrm{pp}$.

Frisch, A. S., B. E. Martner, I. Djalalova, and M. R. Poellot, 2000: Comparison of radar/radiometer retrievals of stratus cloud liquid-water content profiles with in situ measurements by aircraft. Journal of Geophysical Research: Atmospheres, 105, 1536115364, https://doi.org/10.1029/2000JD900128.

Gapp, N. J., J. Schmidt, D. Delene, P. Harasti, J. Hoover, and P. Jones, 2019: Comparisons of Florida Thunderstorm Cirrus Clouds using Concurrent Radar and Aircraft Measurements.

Heymsfield, A. J., 1977: Precipitation Development in Stratiform Ice Clouds: A Microphysical and Dynamical Study. J. Atmos. Sci., 34, 367-381, https://doi.org/10.1175/15200469(1977)034<0367:PDISIC >2.0.CO;2.

_ and J. L. Parrish, 1978: A Computational Technique for Increasing the Effective Sampling Volume of the PMS Two-Dimensional Particle Size Spectrometer. Journal of Applied Meteorology, $\quad \mathbf{1 7}, \quad$ 1566-1572, $\quad$ https://doi.org/10.1175/15200450(1978)017<1566:ACTFIT>2.0.CO;2.

—, A. Bansemer, P. R. Field, S. L. Durden, J. L. Stith, J. E. Dye, W. Hall, and C. A. Grainger, 2002: Observations and Parameterizations of Particle Size Distributions in Deep Tropical Cirrus and Stratiform Precipitating Clouds: Results from In Situ Observations in TRMM Field Campaigns. J. Atmos. Sci., 59, 3457-3491, https://doi.org/10.1175/15200469(2002)059<3457:OAPOPS>2.0.CO;2. 
,-- , C. Schmitt, C. Twohy, and M. R. Poellot, 2004: Effective ice particle densities derived from aircraft data. Journal of the Atmospheric Sciences, 61, 982-1003, https://doi.org/10.1175/1520-0469(2004)061<0982:EIPDDF>2.0.CO;2.

— Z Z. Wang, and S. Matrosov, 2005: Improved Radar Ice Water Content Retrieval Algorithms Using Coincident Microphysical and Radar Measurements. J. Appl. Meteor., 44, 1391-1412.

Horvath, H., R. L. Gunter, and S. W. Wilkison, 1990: Determination of the Coarse Mode of the Atmospheric Aerosol Using Data from a Forward-Scattering Spectrometer Probe. Aerosol Science and Technology, 12, 964-980, https://doi.org/10.1080/02786829008959407.

Houze, R. A., S. G. Geotis, F. D. Marks, D. D. Churchill, and P. H. Herzegh, 1981: Comparison of Airborne and Land-Based Radar Measurements of Precipitation during Winter MONEX. J. Appl. Meteor., $\quad$ 20, $\quad 772-783, \quad$ https://doi.org/10.1175/15200450(1981)020<0772:COAALB $>2.0 . \mathrm{CO} ; 2$.

Hudak, D., B. Currie, P. Rodriguez, S. G. Cober, I. Zawadski, G. A. Isaac, and M. Wolde, 2002: Cloud phase detection in winter stratiform clouds using Polarimetric Doppler Radar. Proceedings of ERAD, European Conference on Radar in Meteorology and Hydrology, Delft, Netherlands, Copernicus GmbH, 90-94.

Jensen, E., D. Starr, and O. B. Toon, 2004: Mission investigates tropical cirrus clouds. Eos, Transactions American Geophysical Union, $\quad \mathbf{8 5}, \quad 45-50$, https://doi.org/10.1029/2004EO050002.

Korolev, A., E. Emery, and K. Creelman, 2013a: Modification and Tests of Particle Probe Tips to Mitigate Effects of Ice Shattering. Journal of Atmospheric and Oceanic Technology, 30, 690-708, https://doi.org/10.1175/JTECH-D-12-00142.1. 
Korolev, A., J. W. Strapp, G. A. Isaac, and E. Emery, 2013b: Improved Airborne Hot-Wire Measurements of Ice Water Content in Clouds. J. Atmos. Oceanic Technol., 30, 2121-2131, https://doi.org/10.1175/JTECH-D-13-00007.1.

Korolev, A. V., J. W. Strapp, G. A. Isaac, and A. N. Nevzorov, 1998: The Nevzorov Airborne Hot-Wire LWC-TWC Probe: Principle of Operation and Performance Characteristics. Journal of Atmospheric and Oceanic Technology, 15, 1495-1510, https://doi.org/10.1175/1520-0426(1998)015<1495:TNAHWL>2.0.CO;2.

Lawson, R. P., and P. Zuidema, 2009: Aircraft Microphysical and Surface-Based Radar Observations of Summertime Arctic Clouds. Journal of the Atmospheric Sciences, 66, 3505-3529, https://doi.org/10.1175/2009JAS3177.1.

—, R. E. Stewart, J. W. Strapp, and G. A. Isaac, 1993: Aircraft observations of the origin and growth of very large snowflakes. Geophys. Res. Lett., 20, 53-56.

— D. O'Connor, P. Zmarzly, K. Weaver, B. Baker, Q. Mo, and H. Jonsson, 2006: The 2D-S (Stereo) Probe: Design and Preliminary Tests of a New Airborne, High-Speed, HighResolution Particle Imaging Probe. Journal of Atmospheric and Oceanic Technology, 23, 1462-1477, https://doi.org/10.1175/JTECH1927.1.

Matrosov, S. Y., 1997: Variability of Microphysical Parameters in High-Altitude Ice Clouds: Results of the Remote Sensing Method. Journal of Applied Meteorology, 36, 633-648, https://doi.org/10.1175/1520-0450-36.6.633.

NOAA, 2017: NEXRAD Technical Information. https://www.roc.noaa.gov/WSR88D/Engineering/NEXRADTechInfo.aspx (Accessed July 20, 2019). 
O’Shea, S. J., J. Crosier, J. Dorsey, W. Schledewitz, I. Crawford, S. Borrmann, R. Cotton, and A. Bansemer, 2019: Revisiting particle sizing using grayscale optical array probes evaluation using laboratory experiments and synthetic data. Atmos. Meas. Tech. Discuss., 1-29, https://doi.org/10.5194/amt-2018-435.

Rinehart, R. E., 2010: Radar for meteorologists: or you, too, can be a radar meteorologist, part III. 5. ed. Rinehart Publ, 482 pp.

Sassen, K., 1987: Ice Cloud Content from Radar Reflectivity. J. Climate Appl. Meteor., 26, 1050-1053, https://doi.org/10.1175/1520-0450(1987)026<1050:ICCFRR>2.0.CO;2.

Sauvageot, H., 1992: Radar meteorology. Artech House, 366 pp.

Sayres, D. S., and Coauthors, 2008: Validation and determination of ice water content-radar reflectivity relationships during CRYSTAL-FACE: Flight requirements for future comparisons. J. Geophys. Res., 113, https://doi.org/10.1029/2007JD008847.

Schmidt, J. M., and Coauthors, 2012: Radar observations of individual rain drops in the free atmosphere. PNAS, 109, 9293-9298, https://doi.org/10.1073/pnas.1117776109.

—, P. J. Flatau, and R. D. Yates, 2014: Convective Cells in Altocumulus Observed with a High-Resolution Radar. J. Atmos. Sci., 71, 2130-2154, https://doi.org/10.1175/JAS-D-130172.1.

—, and Coauthors, 2019: Radar detection of individual cloud hydrometeors. Bull. Amer. Meteor. Soc, In review.

Smith, P., 1984: Equivalent radar reflectivity factors for snow and ice particles. J. Climate Appl. Meteor., 23, 1258-1260.

University of North Dakota, 2004: University of North Dakota | UND Doppler Radar. UND Doppler Radar,. http://radar.atmos.und.edu/ (Accessed July 20, 2019). 
Wang, Z., and K. Sassen, 2002: Cirrus Cloud Microphysical Property Retrieval Using Lidar and Radar Measurements. Part I: Algorithm Description and Comparison with In Situ Data. J. Appl. $\quad$ Meteor., $\quad$ 41, 218-229, $\quad$ https://doi.org/10.1175/15200450(2002)041<0218:CCMPRU>2.0.CO;2.

Wu, W., and G. M. McFarquhar, 2016: On the Impacts of Different Definitions of Maximum Dimension for Nonspherical Particles Recorded by 2D Imaging Probes. J. Atmos. Oceanic Technol., 33, 1057-1072, https://doi.org/10.1175/JTECH-D-15-0177.1. 